\title{
Yeast and its Importance to Wine Aroma - A Review
}

\author{
M.G. Lambrechts and I.S. Pretorius
}

Institute for Wine Biotechnology and Department of Viticulture \& Oenology, University of Stellenbosch, Private Bag X1, 7602 Matieland (Stellenbosch), South Africa

Submitted for publication: June 2000

Accepted for publication: August 2000

Key words: Wine aroma; wine flavour; fermentation bouquet; wine yeast

The most mysterious aspect of wine is the endless variety of flavours that stem from a complex, completely non-linear system of interactions among many hundreds of compounds. In its widest sense, wine flavour refers to the overall impression of both aroma and taste components. Aroma is usually associated with odorous, volatile compounds; the bouquet of wine refers to the more complex flavour compounds which evolve as a result of fermentation, élevage and ageing. With the exception of terpenes in the aromatic grape varieties and alkoxypyrazines in the herbaceous cultivars, perceived flavour is the result of absolute amounts and specific ratios of many of these interactive compounds, rather than being attributable to a single "impact" compound. Without underestimating the complexity of these interactive effects or negating the definitive role played by the accumulated secondary grape metabolites in the varietal character of wine, this review will focus mainly on the contribution of yeast fermentation to the sensorial quality of the final product. Yeast and fermentation conditions are claimed to be the most important factors influencing the flavours in wine. Both spontaneous and inoculated wine fermentations are affected by the diversity of yeasts associated with the vineyard and winery. During the primary alcoholic fermentation of sugar, the wine yeast, Saccharomyces cerevisiae, together with other indigenous non-Saccharomyces species, produce ethanol, carbon dioxide and a number of by-products. Of these yeast-derived metabolites, the alcohols, acetates and C4-C8 $\pi$ fatty acid ethyl esters are found in the highest concentration in wine. While the volatile metabolites contribute to the fermentation bouquet ubiquitous to all young wines, the production levels of these by-products are variable and yeast strain specific. Therefore, this article also highlights the importance of untapping the hidden wealth of indigenous yeast species present on grapes, and the selection and genetic development of yeast starter culture strains with improved flavour profiles. In the future, some winemakers may prefer to use mixtures of indigenous yeast species and tailored $S$. cerevisiae strains as starter cultures to reflect the biodiversity and stylistic distinctiveness of a given region. This will help winemakers to fullfil the consumer's demand for individual wines with intact local character and to ensure the survival of wine's most enthralling aspect - its endless variety.

\section{INTRODUCTION}

Flavour is a wine's most important distinguishing characteristic. A wine's flavour could, in its widest sense, be said to be the overall sensory impression of both aroma (as sensed by nose and from the mouth) and taste compounds, and may therefore incorporate the more measurable aspects of acidity, sweetness, alcoholic strength, fizziness, astringency and bitterness (Robinson, 1994). Whereas flavour refers to the effects of both odour and taste, aroma is purely associated with odorous, volatile compounds, while the bouquet of wine refers to the more complex flavour compounds which evolve as a result of fermentation, élevage and ageing. However, most of what is commonly described as wine's flavour is in fact its aroma or alternatively, in the case of older wines, its bouquet (Robinson, 1994). In this review the word flavour is used interchangeably with aroma and bouquet.

Wine flavour is classified according to the sources of the different compounds contributing to it. This includes varietal flavour (flavour compounds originating from the grapes), prefermentative flavour (compounds formed during operations of extraction and conditioning of must), fermentative flavour (produced by yeast and bacteria during alcoholic and malolactic fermentation) and post-fermentative flavour (compounds that appear during the ageing process through enzymatic or physicochemical actions in wood or in the bottle) (Schreier, 1979; Boulton et al., 1995; Rapp, 1998).

It is well known that the secondary metabolites of grapes are responsible for the principal flavour compounds in grape must, and provide the basis of "varietal character" (Schreier, 1979; Rapp \& Versini, 1991). Various biosynthetic pathways are interactive during the formation of the aroma of alcoholic beverages. Fermentation increases the chemical and flavour complexity of wine by assisting in the extraction of compounds from solids present in grape must, modifying some grape derived compounds, and producing a substantial amount of yeast metabolites.

Volatiles identified in wines are usually dominated by fermentation products, since these volatiles are present in the highest concentration. In a model fermentation with Saccharomyces starting at about 22 to $24 \%$ sugar, $95 \%$ of the sugar is converted to 
ethanol and carbon dioxide, $1 \%$ is converted to cellular material, and the remaining $4 \%$ is converted to other end products (Fig. 1) (Boulton et al., 1995). The major volatile products of yeast metabolism, ethanol, glycerol and carbon dioxide, make a relatively small, but, nonetheless, fundamental contribution to wine flavour. The main groups of compounds that form the "fermentation bouquet" are the organic acids, higher alcohols and esters and, to a lesser extent, aldehydes (Rapp \& Versini, 1991). When present in excess concentrations, some fermentation bouquet compounds may also be regarded as undesirable, such as acetaldehyde, acetic acid, ethyl acetate, higher alcohols and diacetyl. The most "negative" aroma compounds are the reduced sulfur compounds, hydrogen sulfide, organic sulfides and thiols. Fermentative flavour is not only brought about by the conversion of directly fermentable substances, but also by the long-chain fatty acids, organic nitrogen-containing compounds, sulfur-containing compounds and many others. These compounds are able to penetrate from the grape juice medium through the yeast cell wall membrane, where they participate in biochemical reactions producing numerous volatile substances as by-products (Boulton et al., 1995).

There are several yeast genera and species apart from Saccharomyces cerevisiae found on the grapes, in the must and in the wine that can contribute to the flavour of wine (Table 1). To ascertain the contribution of these yeasts to the aroma of wine it is necessary to fully understand their roles in the fermentation process. Therefore, it is essential to know (i) the taxonomic identity of each species contributing to the fermentation; (ii) the kinetics of growth of each species; (iii) the biochemical properties of these yeasts and the chemical changes they produce; and (iv) the influences of vinification factors upon the kinetics of growth and chemical change (Fleet \& Heard, 1993). Although wine yeasts have been extensively investigated over many years, these studies have lacked a quantitative focus.

The microflora of grapes is highly variable, with a predominance of the low alcohol tolerant strains of Hanseniaspora, Kloeckera and various species of Candida, whereas $S$. cerevisiae is present only at low numbers (Peynaud \& Domercq, 1959; Fleet et al., 1984; Heard \& Fleet, 1985; Lema et al., 1996). The influence that all of these yeasts will have on the flavour of wine depends on several factors. The method of grape harvest (handpicked or mechanical), transport (time, temperature and sulfite addition) and the condition of the grapes (temperature, sulfite addition, hygiene, aeration, enzyme treatment, clarification method) all affect the microbial content of grape must. Yeast cell concentrations in freshly prepared must is typically $10^{3}$ to $10^{5}$ $\mathrm{cfu} / \mathrm{ml}$, but after processing may vary from near sterility to $>10^{6}$ yeast $\mathrm{cfu} / \mathrm{ml}$. This highly variable content of yeast populations may contribute to chemical and flavour changes that accompany fermentation.

Grape juice fermentation can either be natural, conducted by the flora present on the grapes and in the winery, or inoculated with a commercial strain of Saccharomyces. Inoculation minimizes the influence of wild yeasts on wine quality, although it has been shown that such cultures may not necessarily prevent the growth and metabolic activity of indigenous, winery-associated strains of S. cerevisiae or other wild yeasts such as Kloeckera apiculata, Hanseniaspora uvarum, Candida stellata and

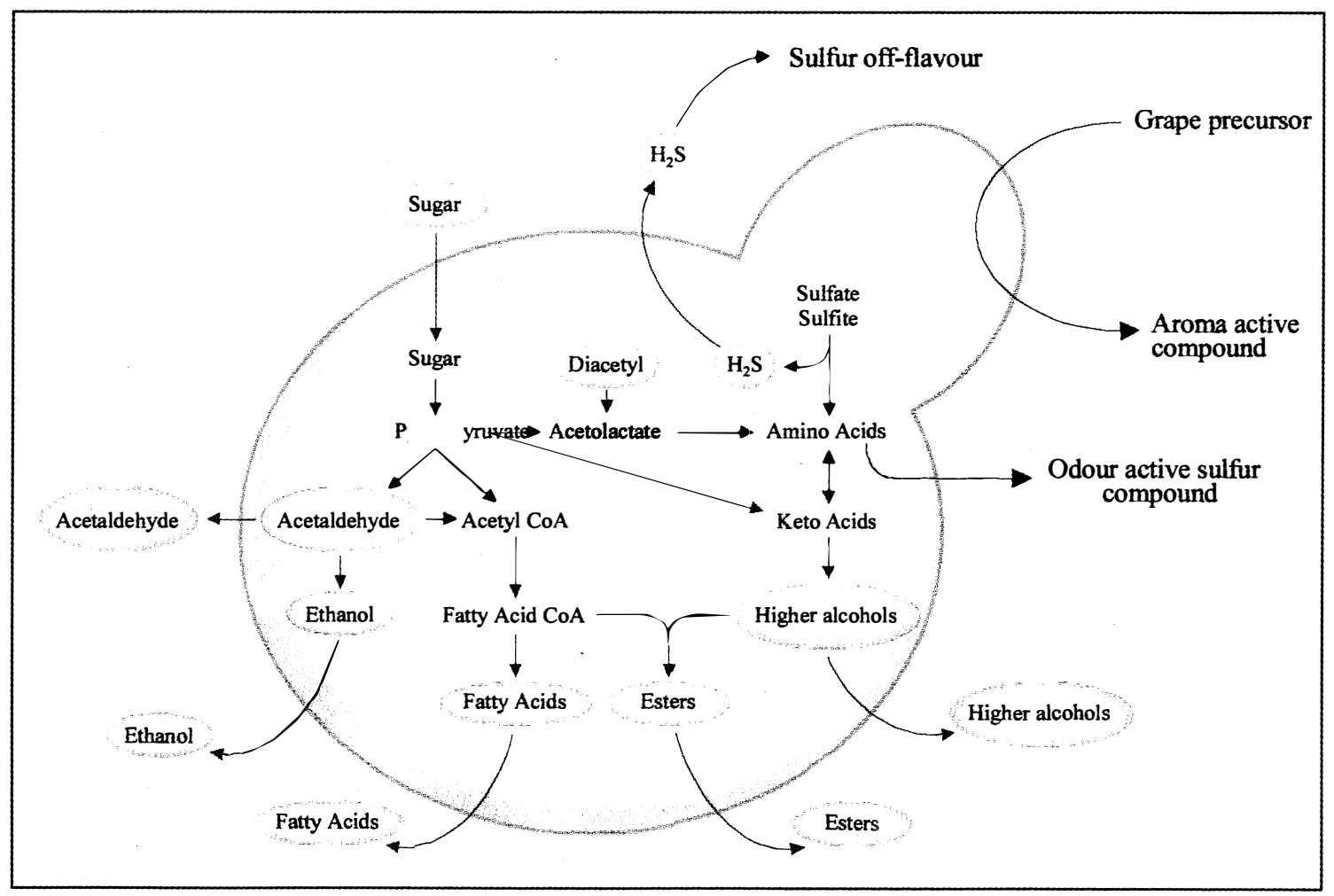

FIGURE 1

A schematic representation of the formation of aroma compounds by yeast (adapted from Henschke \& Jiranek, 1993b). 
TABLE 1

Wine-related yeasts.

\begin{tabular}{|c|c|c|}
\hline Genus & Species & According to Kurtzman \& Fell, 1998 \\
\hline Brettanomyces & $\begin{array}{l}\text { anomalus } \\
\text { bruxellensis } \\
\text { intermedius }\end{array}$ & Brettanomyces bruxellensis \\
\hline Candida & $\begin{array}{l}\text { boidinii } \\
\text { colliculosa } \\
\text { guilliermondii } \\
\text { hellenica } \\
\text { krusei } \\
\text { lambica } \\
\text { oloephila } \\
\text { pelliculosa } \\
\text { pulcherrima } \\
\text { sorbosa } \\
\text { stellata } \\
\text { valida } \\
\text { vanrijiae }\end{array}$ & \\
\hline Cryptococcus & albidus & \\
\hline Debaromyces & hansenii & \\
\hline Dekkera & $\begin{array}{l}\text { anomala } \\
\text { bruxellensis }\end{array}$ & \\
\hline Hanseniaspora & uvarum & \\
\hline Hansenula & $\begin{array}{l}\text { anomala } \\
\text { klugveri }\end{array}$ & $\begin{array}{l}\text { Pichia anomala } \\
\text { Pichia kluyveri var. klugveri }\end{array}$ \\
\hline Kloeckera & apiculata & \\
\hline Kluyveromyces & $\begin{array}{l}\text { marxianus } \\
\text { thermotolerans }\end{array}$ & \\
\hline Metschnikowia & pulcherrima & \\
\hline Pichia & $\begin{array}{l}\text { klugveri } \\
\text { membranifaciens }\end{array}$ & \\
\hline Rhodotorula & glutinis & \\
\hline Saccharomyces & $\begin{array}{l}\text { bayanus } \\
\text { beticus } \\
\text { capensis } \\
\text { cerevisiae } \\
\text { chevalieri } \\
\text { ellipsoideus } \\
\text { fermentati } \\
\text { oviformis } \\
\text { rosei } \\
\text { uvarum }\end{array}$ & $\begin{array}{l}\text { cerevisiae } \\
\text { cerevisiae } \\
\text { cerevisiae } \\
\text { cerevisiae } \\
\text { Torulaspora delbrueckii } \\
\text { cerevisiae } \\
\text { Torulaspora delbrueckii } \\
\text { bayanus }\end{array}$ \\
\hline Saccharomycodes & ludwigii & \\
\hline Schizosaccharomyces & $\begin{array}{l}\text { pombe } \\
\text { japonicus }\end{array}$ & \\
\hline Torulaspora & delbrueckii & \\
\hline Zygosaccharomyces & $\begin{array}{l}\text { bailii } \\
\text { bisporus } \\
\text { florentinus } \\
\text { rouxii }\end{array}$ & \\
\hline
\end{tabular}


Torulaspora delbrueckii (Heard \& Fleet, 1986; Lema et al., 1996; Egli et al., 1998; Henick-Kling et al., 1998). These wild yeasts are capable of anaerobic as well as aerobic growth and may persist during the fermentation, competing with Saccharomyces for nutrients, and may produce fatty acid esters and other compounds affecting the fermentation bouquet of the wine. Very few of these yeasts are as ethanol-tolerant as Saccharomyces, and therefore are generally undetectable by the end of fermentation. The persistence of these non-Saccharomyces, or wild yeasts during fermentation depends upon many factors, such as the temperature of fermentation, nutrient availability, inoculum strength of Saccharomyces, use and levels of sulfur dioxide, and the quantity and identity of organisms initially present on the grapes. According to Fleet et al. (1984), in a natural selection process, the most suitable indigenous strains of $S$. cerevisiae become established in wineries and vineyards; thus it is assumed that wine character may be influenced by the particular strain conducting the fermentation.

Several researchers have shown that in contrast to Saccharomyces species, the non-Saccharomyces yeasts produce and secrete several enzymes (esterases, glycosidases, lipases, Bglucosidases, proteases, cellulases etc.) to the periplasmic space and the medium, where they may interact with grape precursor compounds to produce aroma active compounds, and thus play an important role in varietal aroma (Charoenchai et al., 1997). The activity of these enzymes in must and wine has not been studied extensively and therefore the effect on wine flavour is at present still unclear.

Due to a lack of published hard evidence, the contribution of yeast to the flavour of wine has always been controversial, though there is considerable anecdotal evidence from winemakers and researchers. Studies investigating starter cultures and indigenous yeasts have shown that there are significant differences in the chemical composition of the resultant wines (Mora et al., 1990; Longo et al., 1992; Gafner et al., 1993; Lema et al., 1996). These studies, however, did little to measure sensory differences using tasting panels. More recently, Egli et al. (1998) and Henick-Kling et al. (1998) clearly showed the effect of indigenous and inoculated yeast populations on the sensory character of Riesling and Chardonnay wines. Similarly, Steger \& Lambrechts (2000) showed that different Saccharomyces cerevisiae wine yeasts, used to ferment base wines for brandies, produced wines with varying chemical profiles. These profiles conferred to differences in the sensory evaluation of the wines. Furthermore, it was recently discovered that Sauvignon blanc varietal precursors are transformed during alcoholic fermentation by $S$. cerevisiae into aroma active varietal compounds responsible for the overtones of box tree, broom and passion fruit considered typical of this grape variety (Darriet et al., 1995; Tominagà et al., 1998a). These findings suggest that there might be other varietal compounds, liberated or produced by yeasts, still to be discovered.

This review, summarizing the most important aspects of yeast's contribution to wine flavour, illustrates the importance of (i) thorough biological surveys within the ecological framework of the winemaking process; (ii) thorough surveys of the metabolism and enzymatic activities of these yeasts; and (iii) the organoleptic impact of individual or combinations of species on wine flavour.

\section{BIOCHEMICAL COMPOUNDS ARISING FROM YEAST METABOLISM}

Yeasts may be categorized by their fermentative properties and growth responses to oxygen as obligately fermentative, facultatively fermentative and non-fermentative. Yeasts exhibit diversity in their modes of energy generation; Table 2 categorizes groups of yeasts with respect to their utilization of respiration and fermentation in ATP production (Walker, 1998).

About one third of the yeast species (over 400) studied by Barnett et al. (1979) were categorized as non-fermentative, although such distinctions may be dubious due to the choice of fermentation tests (Scheffers, 1987). During a comparative study on the enzymology of facultatively fermentative and non-fermentative yeast, a variety of yeasts described as non-fermentative contained pyruvate decarboxylase, the key enzyme of alcoholic fermentation. These yeasts were evaluated as to their fermentative capacities. It was found that though these yeasts did not produce gas in the classical Durham-tube test, nearly all strains produced significant amounts of ethanol under the test conditions. It was concluded that the taxonomic test for fermentation capacity, which relies on detection of gas formation in Durham tubes, is unreliable for a physiological classification of yeasts as fermentative or non-fermentative. This might indicate that some of the yeasts shown as non-fermentative in Table 2 might indeed be able to ferment and grow, and therefore contribute to the flavour of wine.

Yeast metabolism refers to the biochemical assimilation (energy consuming) and dissimilation (energy generating) of nutrients by yeast cells (Walker, 1998). These reductive and oxidative processes of anabolism and catabolism are mediated by dehydrogenase enzymes which predominantly use NADP and NAD, respectively as redox co-factors. The formation of NADH and oxidation to NAD are always kept in equilibrum by the cell (the redox balance), thereby preventing the stalling of glycolysis. The formation of aroma compounds by yeast, i.e. esters, fatty acids, fatty acid esters and higher alcohols, is intrinsically linked to the metabolism of yeast cells. Some of these aroma compounds have specific functions in the yeast cell, whereas the function of others is still speculative.

\section{Volatile fatty acids}

Alcoholic beverages contain mainly saturated, straight-chain fatty acids, with palmitoleic acid considered to be the only important unsaturated fatty acid. The volatile acid content of wine usually lies between $500-1000 \mathrm{mg} / \mathrm{L}$ (10-15\% of the total acid content), whereas cognac contains about $200 \mathrm{mg} / \mathrm{L}$. Normally more than $90 \%$ of the volatile acid of wine consists of acetic acid $(>0.2$ - < 2 g volatile acidity/L) (Henschke \& Jiranek, 1993a; Radler, 1993). Acetic acid becomes objectionable near its flavour threshold of 0.7-1.1 g/L, depending on the style of wine, and values between 0.2 and $0.7 \mathrm{~g} / \mathrm{L}$ are considered optimal (Corison et al., 1979; Dubois, 1994a, b). In contrast Riesen (1992) reported perception values of only 0.1-0.25 g/L and Davis et al. (1985) and Henick-Kling (1993) a value of $0.4 \mathrm{~g} / \mathrm{L}$ in delicately flavoured wines. By law the volatile acidity (expressed as acetic acid) of wines may not be higher than 1.0-1.5 g/L, depending on the country (Eglinton \& Henschke, 1999). In the case of base wines for brandy, cognac and armagnac the legal limit is $0.7 \mathrm{~g} / \mathrm{L}$. A variety 
TABLE 2

Principal modes of sugar catabolism in yeasts (Walker, 1998).

\begin{tabular}{|c|c|c|c|c|}
\hline Group name & Examples & Respiration & Fermentation & Anaerobic growth \\
\hline Obligate respirers & $\begin{array}{l}\text { Rhodotorula spp. and } \\
\text { Cryptococcus spp. }\end{array}$ & Yes & No & No \\
\hline Aerobic respires & $\begin{array}{l}\text { Candida spp., } \\
\text { Kluyveromyces spp., } \\
\text { Pichia stipitis and } \\
\text { Pachysolen tannophilus }\end{array}$ & Yes & $\begin{array}{l}\text { Anaerobic in } \\
\text { pregrown cells }\end{array}$ & No \\
\hline Aerobic fermenters & $\begin{array}{l}\text { Schizosaccharomyces } \\
\text { pombe }\end{array}$ & Limited & $\begin{array}{l}\text { Aerobic and } \\
\text { anaerobic }\end{array}$ & No \\
\hline Facultative aerobic & $\begin{array}{l}\text { Saccharomyces } \\
\text { cerevisiae }\end{array}$ & Limited & $\begin{array}{l}\text { Aerobic and } \\
\text { anaerobic }\end{array}$ & $\begin{array}{l}\text { Facultative, but no } \\
\text { growth in absence } \\
\text { of sterols and fatty } \\
\text { acids }\end{array}$ \\
\hline Obligate fermenters & $\begin{array}{l}\text { Torulopsis } \quad \text { (Candida) } \\
\text { pintolopesii }\end{array}$ & No & Anaerobic & Yes \\
\hline
\end{tabular}

of other fatty acids are present in small amounts in wine. The short-chain fatty acids, acetic, propanoic and butanoic acids, are by-products of fermentation, although the presence of propanoic and butanoic acid are associated with the intervention of bacteria (Ribéreau-Gayon et al., 1998). Acetic and lactic acid bacteria can also be associated with high levels of acetic acid.

The long-chain fatty acids (C16 and C18) are essential precursors in the synthesis of many lipid components found in yeast, including mono-, di- and tri-acylglycerols, phospholipids, sphingolipids and a variety of glycolipids (Ratledge \& Evans, 1989). These fatty acids do not occur in a free form in living cells but are normally found as esters, usually of glycerol or sterols (Paltauf $e t$ al., 1992). Unsaturated long chain fatty acids and sterols are an integral part of the yeast plasma membrane, where they are reported to regulate the movement of various compounds into and out of the yeast cell, enhance the ability of yeast to resist high ethanol concentrations and assist the activities of membranebound enzymes in their function (Thurston et al., 1981; Alexandre \& Charpentier, 1998). The unsaturated fatty acids, which play important roles in yeast membrane integrity and ethanol tolerance, include palmitoleic (16:1) and oleic (18:1) acids. Together, these two compounds constitute the bulk (ca. $70 \%$ ) of the fatty acids in S. cerevisiae cell membranes. The others consist mainly of the saturated fatty acids, primarily palmitic acid (16:0), with lesser amounts of stearic (18:0) and myristic (14:0) acids (Ratledge \& Evans, 1989). These fatty acids are not normally found in wine as products from the yeast, but will be found in distilled products in which the distillation is carried out with yeast lees. Residues of linoleic and occasionally linolenic acid can usually be attributed to fatty acids inadvertently present in the original medium.

Medium-chain (C8, C10 and C12), volatile fatty acids are produced by yeasts as intermediates in the biosynthesis of long-chain fatty acids, rather than as a result of acid catabolism. Mediumchain fatty acids and their ethyl esters are natural components of alcoholic beverages. These fatty acids can also act as potential inhibitors of alcoholic fermentation. This inhibiting power on yeast growth is directly proportional to their solubility, which is strictly dependent upon the content of ethanol in the fermentation medium (Walenga \& Lands, 1975; Lafon-Lafourcade et al., 1984; Sa-Correia et al., 1989; Viegas et al., 1989). Table 3 lists the odours associated with some of the more prominent volatile fatty acids and their average concentration levels in wine as produced by yeast during fermentation.

In considering the total lipid content of yeasts, Ratledge \& Evans (1989) classified yeast as either oleaginous or non-oleaginous, with the somewhat arbitrary division at about a 20 to $25 \%$ lipid content. The non-oleaginous group encompasses the vast majority of yeasts and includes $S$. cerevisiae. The oleaginous group is much smaller, and includes species of Lipomyces and Rhodotorula. A third category of lipid-producing yeasts could be considered for those yeasts that produce extracellular lipids. Although the non-Saccharomyces yeasts found on grapes have not been tested for their lipid content, most if not all would probably fall into the non-oleaginous group.

Biosynthesis of fatty acids by yeasts: Pathways leading to fatty acid synthesis have been intensively studied for $S$. cerevisiae (for recent reviews see: Ratledge \& Evans, 1989; Paltauf et al., 1992). The formation of acetyl coenzyme A (acetyl-CoA) is the first step in the biosynthesis of fatty acids (Fig. 2) (Lynen, 1967). Acetyl$\mathrm{CoA}$ is formed by the oxidative decarboxylation of pyruvic acid. Further synthesis of long-chain saturated fatty acids occurs via two enzyme systems: acetyl-CoA carboxylase and fatty acid synthetase. Acetyl-CoA carboxylase first converts acetyl-CoA into malonyl-CoA, which is utilized by the fatty acid synthetase complex that carries out repetitive condensation between enzymebound acetyl-CoA and malonyl-CoA for the synthesis of saturated fatty acids and for chain elongation (Ratledge \& Evans, 1989; Paltauf et al., 1992). Propionyl-CoA replaces acetyl-CoA in the biosynthesis of the odd numbered fatty acids. 
TABLE 3

Some volatile fatty acids produced by yeast and their concentrations, threshold values and odours in wine (Salo, 1970a; Ribéreau-Gayon et al., 1982; Baumes et al., 1986, 1988; Miranda-Lopez et al., 1992; Riesen, 1992; Dubois, 1994a, b).

\begin{tabular}{|c|c|c|c|}
\hline Compound & $\begin{array}{l}\text { Conc. in wine } \\
(\mathrm{mg} / \mathrm{L})\end{array}$ & $\begin{array}{l}\text { Threshold } \\
(\mathrm{mg} / \mathrm{L})\end{array}$ & Odour \\
\hline Formic acid & 50 & & \\
\hline Acetic acid & $150-900$ & $\begin{array}{c}700-1000 \\
100-125 \\
400\end{array}$ & Vinegar, pungent \\
\hline Propionic acid & Traces & $20.0^{*}$ & Rancid, slightly pungent \\
\hline Butyric acid & Traces & $2.2 / 4.0^{*}$ & Pungent \\
\hline Isobutyric acid & Traces & $8.1^{*}$ & Pungent, less than butyric acid \\
\hline Valeric acid & Traces & & Unpleasant \\
\hline Isovaleric acid & $<3$ & $0.7^{*}$ & $\begin{array}{l}\text { rancid, cheese, sweaty, at times } \\
\text { putrid, stinky }\end{array}$ \\
\hline 2-Methylbutyric acid & $?$ & & \\
\hline Hexanoic acid & Traces-37 & $\begin{array}{c}8 \\
8.8^{*}\end{array}$ & $\begin{array}{l}\text { sour, vinegar, cheese, sweaty, } \\
\text { rancid, fatty, pungent }\end{array}$ \\
\hline Heptanoic acid & Traces & & \\
\hline Octanoic acid & Traces- 41 & $\begin{array}{c}13 \\
15^{*}\end{array}$ & $\begin{array}{l}\text { oily, fatty, rancid, soapy, sweet, } \\
\text { faint fruity, butter }\end{array}$ \\
\hline Nonanoic acid & $?$ & & \\
\hline Decanoic acid & Traces-54 & $\begin{array}{c}10 \\
8.2^{*}\end{array}$ & $\begin{array}{l}\text { fatty, unpleasant, rancid, citrus, } \\
\text { phenolic }\end{array}$ \\
\hline Tridecanoic acid & $15-118$ & & fatty, citrus, unpleasant \\
\hline
\end{tabular}

The synthesis of long-chain, mono-unsaturated fatty acids in yeasts involves an oxidative desaturation by a fatty acid desaturase, to introduce double bonds into the saturated fatty acid. The requirement for oxygen in the desaturase-mediated synthesis of essential unsaturated fatty acids means that $S$. cerevisiae cannot grow strictly anaerobically in the absence of these compounds (Walker, 1998).

Under certain growth conditions (as in the case of a wine fermentation), yeast cells depend on the uptake of exogenous unsaturated fatty acids or ergosterol. Such is the case when fatty acid desaturation or sterol biosynthesis is suppressed by the absence of oxygen or by mutations affecting the synthesis of unsaturated fatty acids and/or sterols (Ratledge \& Evans, 1989). S. cerevisiae is normally unable to degrade fatty acids by $\beta$-oxidation (Johnston \& Paltauf, 1970). A peroxisomal ß-oxidation system can, however, be induced by incubating yeast in the presence of oleic acid (Veenhuis et al., 1987).

The grape contains 0.15 to $0.24 \%$ (wet weight basis) of total lipids. Among the fatty acids present in grapes, unsaturated fatty acids represent the major component of total lipids. Linoleic acid is the most abundant, followed by oleic, linolenic and palmitoleic acid (Gallender \& Peng, 1980; Castella et al., 1985). Among saturated fatty acids, palmitic acid is the most abundant. The fatty acid content varies according to technological procedures applied to the must. Some researchers have found that clarification drastically reduces the content of fatty acids in the resultant wine and can result in stuck fermentations (Delfini \& Costa, 1993). Others have demonstrated that the addition of lipids, especially ergosterol and unsaturated long-chain fatty acids, can have a pronounced effect on the growth and metabolism of yeast (Andreasen \& Stier, 1954; Maurico et al., 1990; Rosi \& Bertuccioli, 1992).

Delfini et al. (1992) also investigated the evolution of fatty acids, acetaldehyde, acetic and pyruvic acid production during fermentation. They noted that, among the two S. cerevisiae strains tested, a large amount of fatty acids is released during the first days of alcoholic fermentation, reaching maximum levels on the $4^{\text {th }}$ and $5^{\text {th }}$ day. This was followed by a decrease around the $7^{\text {th }}$ and $8^{\text {th }}$ days, and a levelling off at lower values, although still rather high, until the end of fermentation. For both strains tested in the study, the production of acetic acid was very high during the first phases of fermentation, reaching a maximum the $5^{\text {th }}$ to $7^{\text {th }}$ days.

Houtman \& Du Plessis (1981) found that the yeast cell obtains 


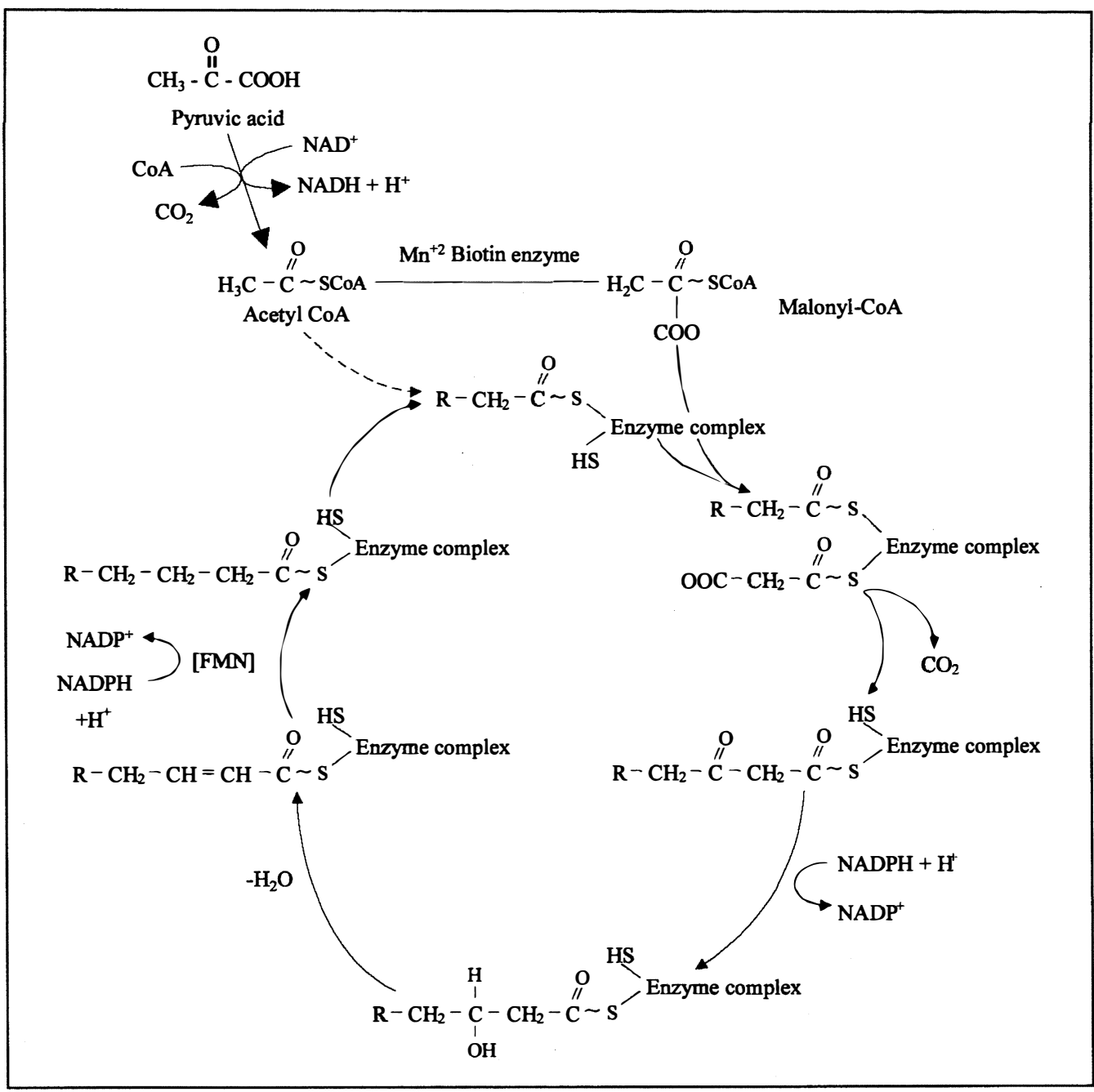

FIGURE 2

A schematic representation of fatty acid biosynthesis (adapted from Lynen, 1967).

substances from the grape juice clarification deposit causing it to limit or even prevent the release of acetic acid in the fermenting medium. These ill-defined substances increase in the must, especially with pressing of skins, and their utilization by yeasts seems to be mediated by enzymes belonging to the yeasts and/or to musts. This was also observed by Delfini \& Cervetti (1987). Furthermore, amounts greater than $1 \mathrm{~g} / \mathrm{L}$ of acetic acid are synthesized in free run musts which were clarified by cooling, adjuvants, decantation, centrifugation or filtration. They also showed that the ammonium concentration has no influence on acetic acid production; however, a small decrease can be observed by addition of methionine, alanine and cysteine.

Rosi \& Bertuccioli (1992) tested the effect of fatty acid and triglyceride mixtures on the fatty acid composition of yeast cells under simulated vinification conditions. Their results showed a significant relationship between fatty acid composition of cells and secretion into the medium of esters, higher alcohols and medium-chain fatty acids. During the first six days of fermentation, the content of linoleic and linolenic acid of yeast was correlated positively to the secretion of isobutanol and isoamyl alco- hol, and negatively to isoamyl acetate and octanoic and decanoic acid of fermented samples. During the latter part of fermentation the content of octanoic, decanoic, dodecanoic and cis-9-hexadecanoic acids of yeast cells was positively correlated to the secretion of ethyl octanoate, ethyl decanoate, ethyl acetate, isoamyl acetate, and medium-chain fatty acids and negatively correlated to isobutanol, active amyl alcohol and isoamyl alcohol. The different pattern of flavour active compounds also correlated to the descriptive sensory analysis of the four aroma attributes (banana, artificial fruit, fusel alcohol, soapy). Therefore, any environmental or genetic manipulation of yeast which brings about a specific change in lipid composition is a potential method for controlling the sensory quality of wine.

Yeasts synthesize much the same fatty acids irrespective of the nature of raw materials used. However, the fatty-acyl composition of yeasts is highly variable; changes in growth substrate and minor alterations in growth conditions $\mathrm{pH}$ value, temperature, dissolved oxygen tension, presence/absence of major or minor nutrients) as well as the growth rate of the organism itself may affect the relative proportions of the individual components 
(Paltauf et al., 1992). Furthermore, the amount and portion of medium-chain fatty acids released into the fermentation medium is strictly dependent on yeast strain, the composition of the medium, and fermentation conditions such as $\mathrm{pH}$, temperature, and degree of aeration during fermentation.

Yeast strain effect on volatile fatty acid production: Although acetic acid and lactic acid bacteria can be responsible for high levels of acetic acid in wine, so can the yeasts involved in the winemaking process. Acetic acid formation by strains of $S$. cerevisiae is affected by sugar concentration, $\mathrm{pH}$ and nitrogen (Shimazu \& Watanabe, 1981, as quoted by Henschke \& Jiranek, 1993b; Hannemann, 1985). This was confirmed by Monk \& Cowley (1984), who also found that the addition of $5 \mathrm{mg} / \mathrm{L}$ nicotinic acid to a synthetic medium enhanced the formation of acetic acid at low and high sugar concentrations. Hanneman (1985) found that among 100 strains of various genera, 13 strains of $S$. cerevisiae produced more than $1 \mathrm{~g} / \mathrm{L}$ of acetic acid in a synthetic medium. Acetic acid is formed early in fermentation and its production stops as soon as the sugar is fermented. Generally, more acetic acid is produced under conditions that are growth limiting. Increasing amounts of acetic acid is produced below $\mathrm{pH}$ 3.2 and at values more neutral than $\mathrm{pH} 4$ (Hanneman, 1985; Delfini \& Cervetti, 1987).

Delfini \& Cervetti (1991) separated Saccharomyces strains into three distinct classes: low $(0.0$ to $0.3 \mathrm{~g} / \mathrm{L})$, medium $(0.31$ to $0.60 \mathrm{~g} / \mathrm{L}$ ) and high (more than $0.61 \mathrm{~g} / \mathrm{L}$ ) acetic acid producers. In particular, all Saccharomyces uvarum strains produced very low amounts of acetic acid. These strains also produced the lowest levels of volatile acidity (ca. $0.1 \mathrm{~g} / \mathrm{L}$ ) of the 23 strains tested. Several studies have shown that strains of, for example, $K$. apiculata (1-2.5 g/L), C. stellata (1-1.3 g/L), Metschnikovia pulcherrima $(0.1-0.15 \mathrm{~g} / \mathrm{L})$, C. krusei $(1 \mathrm{~g} / \mathrm{L})$ and $H$. anomala $(1-2 \mathrm{~g} / \mathrm{L})$ have the potential to produce greater or lesser concentrations of acetic acid than S. cerevisiae (0.3-1.2 g/L) (Hanneman, 1985; Fleet \& Heard, 1993).

Ravaglia \& Delfini (1993) also classified 48 yeast strains into three homogeneous groups with regard to their C8 and C10 fatty acid production (Table 4). Few fatty acids were produced by Zygosaccharomyces bailii, K. apiculata and Schizosaccharomyces japonicus. Saccharomyces cerevisiae var. cerevisiae and $S$. cerevisiae var. bayanus produced the highest amounts, recording $0.9-7 \mathrm{mg} / \mathrm{L}$ of octanoic acid. The only strains that produced detectable amounts of ethyl caprylate were $S$. cerevisiae var. bayanus and $S$. japonicus. Thus, the content of fatty acids as well as their ethyl esters present in wine depend on the strain used during alcoholic fermentation.

Herraiz et al. (1990) studied the influence of pure, mixed and sequential cultures of $K$. apiculata, T. delbrueckii and S. cerevisi$a e$ on the volatile composition of wines obtained without the addition of sulphur dioxide. Their data (Table 5) show clearly that $S$. cerevisiae produces high amounts of caproic, caprylic and capric acids; $T$. delbrueckii and $K$. apiculata producing lower amounts. However, $K$. apiculata gives rise to notable amounts of lauric, myristic, palmitic and palmitoleic acids, and T. delbrueckii produces high levels of isobutyric acid (Herraiz et al., 1990).

TABLE 4

Production of fatty acids and esters by wine yeasts in a synthetic nutrient medium (adapted from Ravaglia \& Delfini, 1993).

\begin{tabular}{|c|c|c|c|c|c|c|}
\hline Strains & $\begin{array}{c}\mathbf{C}_{8} \\
(\mu \mathrm{g} / \mathrm{L})\end{array}$ & $\begin{array}{c}C_{10} \\
(\mu \mathrm{g} / \mathrm{L})\end{array}$ & $\begin{array}{c}\mathrm{C}_{12} \\
(\mu \mathrm{g} / \mathrm{L})\end{array}$ & $\begin{array}{l}\text { Eth-C } \\
(\mu \mathrm{g} / \mathrm{L})\end{array}$ & $\begin{array}{c}\text { Eth-C } C_{10} \\
(\mu \mathrm{g} / \mathrm{L})\end{array}$ & $\begin{array}{c}\text { Eth-C } C_{12} \\
(\mu \mathrm{g} / \mathrm{L})\end{array}$ \\
\hline \multicolumn{7}{|l|}{ High Producers } \\
\hline S. bayanus & 3094 & 1126 & 0 & 250 & 0 & 0 \\
\hline S. bayanus & 3425 & 1568 & 0 & 258 & 0 & 35 \\
\hline S. cerevisiae & 3693 & 2532 & 81 & 59 & 0 & 0 \\
\hline S. cerevisiae & 7066 & 1327 & 46 & 29 & 34 & 0 \\
\hline \multicolumn{7}{|c|}{ Medium Producers } \\
\hline S. bayanus & 1980 & 546 & 0 & 597 & 0 & 0 \\
\hline S. fermentatii & 1813 & 285 & 0 & 0 & 0 & 0 \\
\hline S. exiguus & 1364 & 160 & 0 & 0 & 0 & 0 \\
\hline S. chevalieri & 1769 & 250 & 0 & 0 & 0 & 0 \\
\hline \multicolumn{7}{|l|}{ Low Producers } \\
\hline S. cerevisiae & 286 & 137 & 0 & 0 & 0 & 0 \\
\hline S. ludwigii & 255 & 142 & 0 & 0 & 0 & 0 \\
\hline Z. bailii & 40 & 0 & 0 & 0 & 0 & 0 \\
\hline K. apiculata & 23 & 110 & 0 & 0 & 0 & 0 \\
\hline S. japonicus & 0 & 21 & 0 & 275 & 13 & 0 \\
\hline
\end{tabular}




\section{Higher alcohols}

The term higher alcohols refers to those possessing more than two carbon atoms with a higher molecular weight and boiling point than ethanol. Higher alcohols are quantitatively the largest group of aroma compounds in alcoholic beverages, and are secondary products of alcoholic fermentation (Amerine et al., 1980). Higher alcohols, also known as fusel alcohols, can be recognized by their strong, pungent smell and taste and can have a significant influence on the taste and character of wine and brandy. Although they exhibit a harsh, unpleasant aroma at the concentrations generally found in wine (unless the must contains a high level of suspended solids), below $300 \mathrm{mg} / \mathrm{L}$ they usually contribute to the desirable complexity of wine. When their concentrations exceed $400 \mathrm{mg} / \mathrm{L}$, the higher alcohols are regarded as a negative influence on the quality of the wine (Rapp \& Mandery, 1986). Their overall presence in wine covers a wide range: from a concentration slightly less than $100 \mathrm{mg} / \mathrm{L}$ to a concentration higher than $500 \mathrm{mg} / \mathrm{L}$ (Nykänen, 1986). Generally white wine varieties contain lower fusel alcohol concentrations than red varieties, but some white varieties, such as Semillon, almost always yield high concentrations (Guymon, 1972). Higher alcohols can be of major importance in wine distillates, in which they are much more concentrated (Boulton et al., 1995).

Higher alcohols are composed of aliphatic and aromatic alcohols (Nykänen et al., 1977). Table 6 lists some of the more prominent higher alcohols produced by yeast during fermentation. The aliphatic alcohols include propanol, isobutyl alcohol, active amyl alcohol and isoamyl alcohol; the aromatic alcohols of which phenethyl alcohol is the most important. Besides phenethyl alcohol, the other major phenolic alcohol in wine is tyrosol. This yeast-synthesized phenol has a mild, beeswax, honey-like odour. Whether it plays a role in the honey-like bouquet of certain wines, such as botrytised wines, is unknown (Dubois, 1983). Isoamyl alcohol is the main aliphatic fusel alcohol synthesized by yeast during fermentation. Depending on the nature of the beverage, it comprises $40-70 \%$ of the total fusel alcohol fraction. Other important higher alcohols are propanol, isobutyl alcohol and optically active amyl alcohol. The two amyl alcohols constitute the most abundant minor components or congeners of brandy and other distilled spirits (Nykänen et al., 1977). Viticultural conditions and the use of different yeasts contribute to considerable variations in the quantity of higher alcohols (Giudici et al., 1990). Higher alcohols are also important precursors for ester formation (Soles et al., 1982), and the esters of higher alcohols are associated with pleasant aromas.

Rankine (1967) determined the taste threshold levels of some prominent higher alcohols (isoamyl alcohol, isobutyl alcohol and 1-propanol) in wine and a model solution, showing that differences in amounts of isoamyl alcohol capable of being formed by Saccharomyces can influence the taste of wines, depending on the taster. Differences in the amounts of isobutyl alcohol and 1propanol produced by different yeasts do not affect wine aroma; however this does not take into account the other constituents in wine or the synergism between these compounds contributing to a pungent smell.

Biosynthesis of higher (fusel) alcohols by yeast: Higher alcohols are produced by yeasts during alcoholic fermentation through the conversion of the branched chain amino acids present in the medium: valine, leucine, isoleucine, threonine and phenylalanine (Table 6). They are also produced de novo from a sugar substrate (Fig. 3a, b) (Äyrapää, 1961, 1962, 1965, 1967, 1968 \& 1972). The Ehrlich mechanism or catabolic formation of higher alcohols involves the initial transamination between an amino acid and an $\alpha$-keto acid with subsequent decarboxylation and reduction. The $\alpha$-keto acids produced in the first step may be secreted by yeast or they may be decarboxylated, and subsequently reduced to the fusel alcohol (Zoecklein et al., 1995). The final reduction step involves the reoxidation of $\mathrm{NADH}+\mathrm{H}^{+}$to $\mathrm{NAD}^{+}$, and thus helps to maintain the redox balance within the cell (Van Dijken \& Scheffers, 1986; Quain, 1988; Zoecklein et al., 1995). However,

\section{TABLE 5}

Fatty acid composition in wines resulting from fermentation with $K$. apiculata (A), T. delbrueckii (B) and $S$. cerevisiae (C) in pure, mixed $(\mathrm{AB}, \mathrm{AC}, \mathrm{BC}, \mathrm{ABC})$ and sequential inoculations $(\mathrm{A}+\mathrm{C}, \mathrm{A}+\mathrm{B}+\mathrm{C})$ (Herraiz et al., 1990).

\begin{tabular}{lccccccccc}
\hline Compound (mg/L) & $\mathbf{A}$ & $\mathbf{B}$ & $\mathbf{C}$ & $\mathbf{A B}$ & $\mathbf{A C}$ & $\mathbf{B C}$ & $\mathbf{A B C}$ & $\mathbf{A}+\mathbf{C}$ & $\mathbf{A}+\mathbf{B}+\mathbf{C}$ \\
\hline Butyric acid & 0.05 & 0.1 & 0.11 & 0.25 & 0.17 & 0.21 & 0.19 & 0.11 & 0.06 \\
Isobutyric acid & 0.48 & 3.42 & 0.4 & 6.13 & 0.61 & 1.18 & 0.95 & 0.74 & 0.74 \\
Isovaleric acid & 0.26 & 2.15 & 2.08 & 3.05 & 3.22 & 2.52 & 1.83 & 0.62 & 0.54 \\
Hexanoic acid & 0.45 & 0.19 & 3.18 & 0.16 & 2.5 & 3.23 & 2.54 & 0.71 & 0.41 \\
Octanoic acid & 0.38 & 0.75 & 4.21 & 0.7 & 3.92 & 4.55 & 3.96 & 0.98 & 0.69 \\
Decanoic acid & 0.24 & 0.16 & 0.99 & 0.12 & 1.29 & 1.21 & 0.91 & 0.25 & 0.19 \\
Dodecanoic acid & 0.26 & 0.04 & 0.1 & 0.05 & 0.14 & 0.1 & 0.1 & 0.04 & 0.07 \\
Tetradecanoic acid & 0.1 & 0.08 & 0.04 & 0.08 & 0.09 & 0.09 & 0.06 & 0.04 & 0.07 \\
Hexadecanoic acid & 0.4 & 0.19 & 0.1 & 0.17 & 0.19 & 0.26 & 0.24 & 0.23 & 0.22 \\
Cis-9-hexadecanoic acid & 0.15 & 0.02 & 0.03 & 0.02 & 0.14 & 0.03 & 0.04 & 0.02 & 0.14 \\
\hline
\end{tabular}


TABLE 6

Some higher alcohols produced by yeast and their concentrations, threshold values and odours in wine (Rankine, 1968; Salo, 1972; Shinohara \& Watanabe, 1976; Ribéreau-Gayon et al., 1982; Baumes et al., 1986; Nykänen, 1986; Renger et al., 1992; Dubois, 1994; Zoeklein et al., 1995; Cabanis \& Cabanis, 1998)

\begin{tabular}{llccl}
\hline Compound & \multicolumn{1}{c}{ Amino acids } & $\begin{array}{c}\text { Conc. in wine } \\
\mathbf{m g} / \mathbf{L}\end{array}$ & $\begin{array}{c}\text { Threshold } \\
\text { value (mg/L) }\end{array}$ & Odour \\
\hline Propanol & Threonine/2-Amino-butyric & $9-68$ & $500^{\dagger}$ & Stupefying \\
& acid & 125 & $800^{\ddagger}$ & \\
Butanol & - & $0.5-8.5$ & & Fusel odour
\end{tabular}

\begin{tabular}{|c|c|c|c|c|}
\hline Isobutyl alcohol & Valine & $\begin{array}{c}9-28(100) \\
140^{\prime}\end{array}$ & $\begin{array}{c}500^{\dagger} \\
75.0^{*} \\
200^{\ddagger}\end{array}$ & Alcoholic \\
\hline Active amyl alcohol & Isoleucine & $15-150$ & $65^{\ddagger}$ & Marzipan \\
\hline Isoamyl alcohol & Leucine & $45-490$ & $\begin{array}{c}300^{\dagger} \\
7.0^{*} \\
70^{\ddagger}\end{array}$ & Marzipan \\
\hline Hexanol & - & $0.3-12$ & $\begin{array}{c}5.2^{*} \\
4^{\ddagger}\end{array}$ & \\
\hline Tyrosol & Tyrosine & & & Bees wax, honey-like \\
\hline Tryptophol & Tryptophan & & & \\
\hline Phenethyl alcohol & Phenylalanine & $10-180$ & $\begin{array}{l}7.5^{*} \\
125^{\ddagger}\end{array}$ & Floral, rose \\
\hline
\end{tabular}

according to Boulton et al. (1995) the exact function of higher alcohols is unknown and this reaction is not considered to be an important means for the reoxidation of $\mathrm{NADH}$, since, they reason, there appears to be enough acetaldehyde to help maintain the redox balance. Higher alcohol formation may simply serve to detoxify any aldehydes produced during amino acid catabolism or may be involved in the regulation of amino acid anabolism (Boulton et al. 1995). Physiologically, oxidative deamination provides the yeast with a mechanism for obtaining more nitrogen when the pool has become depleted (Vollbrecht \& Radler, 1973).

The metabolism of the amino acids to higher alcohols is restricted to the exponential growth phase (Vollbrecht \& Radler, 1973). Guymon et al. (1961) have shown that propanol and the branched chain C4 and C5 alcohols, all of which appear as major components in alcoholic beverages, are formed from valine, leucine and isoleucine (Table 6). $\propto$-Ketobutyric acid acts as an intermediate in the formation of propanol, and it is also an intermediate in the formation of active amyl alcohol. Reazin et al. (1973) investigated the effect of threonine and isoleucine on the formation of higher alcohols. They showed that in S. cerevisiae, isoleucine forms active amyl alcohol as almost the only product, whereas threonine produces propanol, active amyl alcohol and isoamyl alcohol. Webb \& Ingraham (1963) reported that isobutyl alcohol is formed from pyruvic acid via $\propto$-keto-isovaleric acid.

Parts of the enzymatic pathways needed for formation of the corresponding amino acids are utilized for the anabolic formation of higher alcohols from sugars. Peynaud \& Guimberteau (1962) estimated that no more than one sixth of the leucine and valine in grape musts assimilated during fermentation gave rise to isoamyl and isobutyl alcohols respectively. Peynaud \& Guimberteau (1962) felt that since these amino acids are low in grape musts, the formation of higher alcohols by amino acid degradation is negligible. Instead, nearly all of the higher alcohols are derived from carbohydrate degradation. All routes for the formation of higher alcohols lead to $\propto$-keto acids which can, apart from being decarboxylated to an aldehyde and reduced to the corresponding alcohol (Ehrlich - Neubauer and Fromherz degradation), participate in one or more of several other reactions. Using radioactive tracers, Reazin et al. (1970) found that $35 \%$ of higher alcohols arose from carbohydrates.

The amino acids in a medium are among the most important factors influencing fusel alcohol formation. They are able to alter the yield of higher alcohols in several different ways (Schulthess \& Ettlinger, 1978). Amino acids contribute to the total nitrogen content of the medium, and the amount of fusel alcohols formed by the anabolic pathway (from carbohydrates) depends to a great 


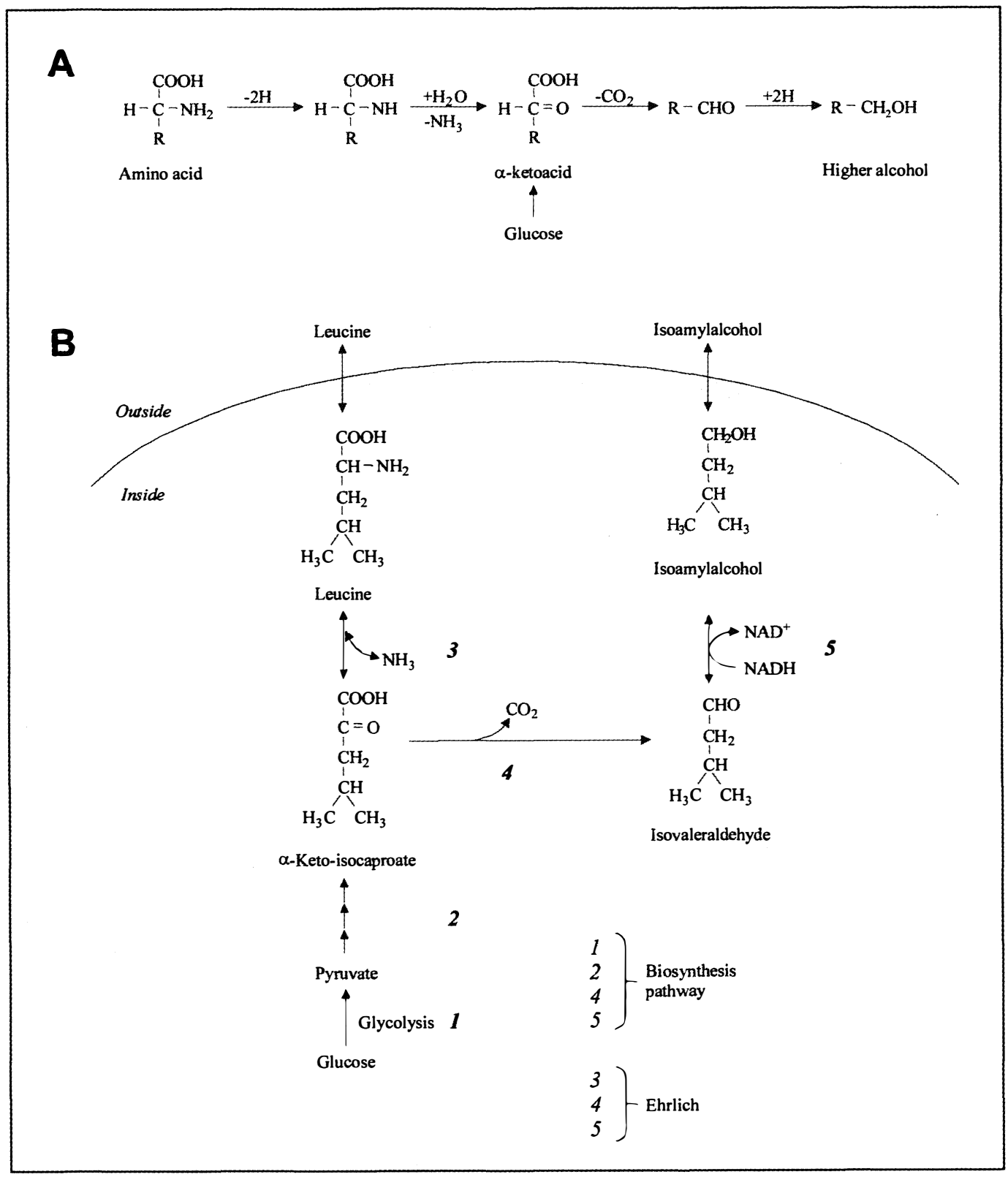

FIGURE 3

A) Generalized pathway for formation of higher alcohols (fusel oils) from amino acid and $\propto$-keto acid precursors. B) Formation of isoamyl alcohol via the anabolic and catabolic pathways (adapted from Boulton et al., 1995; Walker, 1998).

extent on the nitrogen level. Äyrapää (1968) showed that the closer the nitrogen concentration is to the growth-limiting level, the higher is the yield of anabolic fusel alcohols. Both catabolic and anabolic synthesis can be decreased by the addition of nitrogen. The total yield of higher alcohols can also be diminished, even with the addition of branched chain amino acids, if the total nitrogen content at the beginning of fermentation is low. On the other hand, the addition of valine, leucine or isoleucine to a fermentation medium may increase the total formation of the corresponding higher alcohols, although obviously the influence of nitrogen in such a case is of a second order (Pierce, 1987).

Amino acids can influence the anabolic formation of their corresponding higher alcohols by inhibiting the biosynthetic enzymes. This has been shown for the formation of isobutyl, active amyl and isoamyl alcohol on the biosynthetic pathway of valine, isoleucine and leucine (Boulton et al., 1995). Amino acids can also be converted directly into higher alcohols. This catabolic pathway is known as the Ehrlich mechanism.

The question arises as to what extent the catabolic and anabolic formation of fusel alcohol changes, if the medium, in addition to possessing a sufficient amount of nitrogen, is supplied with branched chain amino acids. Schulthess \& Ettlinger (1978) showed that the total and catabolic production of higher alcohols increases with increasing concentrations of the corresponding amino acids, and that the anabolic pathway can be suppressed by high levels of the corresponding amino acid. Giudici et al. (1993) 
observed that the differences in the amount of higher alcohols in various wines, irrespective of the yeast strain used to ferment the original juice, could be due to the must composition in general or, in particular, to differences in the amino acid content of the juices. They found that, despite the fact that low amounts of amino acids were present with respect to the quantity of corresponding higher alcohols formed (via the Ehrlich reaction), the amino acids may play a role in controlling the pathways of their own formation and thus influence the anabolic formation of the higher alcohols. This was shown to be the case for isobutanol, active amyl and isoamyl alcohol (Schulthess \& Ettlinger, 1978).

Yeast strain, yeast growth, ethanol production, fermentation temperature, must $\mathrm{pH}$, aeration, level of solids, grape variety and maturity and skin contact time all affect the production of each alcohol in different ways (Fleet \& Heard, 1993).

Yeast strain effect on higher alcohol formation: Early studies by Webb \& Kepner (1961) showed that Burgundy, Jerez and Montrachet yeasts differed considerably in the relative proportion of specific higher alcohols produced. Rankine (1967) examined several species of Saccharomyces as well as native yeast species with respect to higher alcohol production in wine (Table 7). In the case of pure culture Saccharomyces fermentations, significant differences in the concentrations of various higher alcohol fractions (most notably 1-propanol) were observed. In mixed culture fermentations where the population of the native yeast was low, fusel alcohol levels were not substantially different from those of pure culture Saccharomyces fermentations. Giudici et al. (1990) examined one hundred strains of $S$. cerevisiae for the ability to produce higher alcohols. The production of higher alcohols was found to be an individual strain characteristic (strains were divided into high and low producers), and as such was statistically significant. The characteristics of the strains used were found to be uncorrelated to isobutanol and isoamyl alcohol production, whereas the production of high levels of 1-propanol was found to be related to the inability to produce $\mathrm{H}_{2} \mathrm{~S}$. The ability of strains to produce different amounts of higher alcohols can be used as a determining character in yeast selection for industrial purposes.
For the production of isoamyl alcohol, isobutanol and propanol the concentrations ranged from 5 to $18 \mathrm{mg} / \mathrm{L}, 3$ to $11 \mathrm{mg} / \mathrm{L}$ and 5 to $58 \mathrm{mg} / \mathrm{L}$, respectively. Similar results were obtained by Giudici et al. (1993) under enological conditions.

Antonelli et al. (1999) studied 13 different yeasts for their secondary product formation during alcoholic fermentation. They found two $S$. cerevisiae yeasts that produced high quantities of 3ethoxypropanol, correlated to a high propanol content. Di Stefano et al. (1981) reported this compound as typical of certain yeast strains, and its concentration was recently shown to increase significantly during flor ageing of Vernaccia di Oristano wine. Herraiz et al. (1990) found comparable amounts of this alcohol produced by $T$. delbrueckii, but with no correlation to $n$-propanol content.

Herraiz et al. (1990) investigated the influence of pure, mixed and sequential cultures of $K$. apiculata, $T$. delbrueckii (formerly Saccharomyces rosei) and $S$. cerevisiae on the volatile composition of wines. The results clearly showed that growth of $K$. apiculata and $T$. delbrueckii prior to the inoculation of $S$. cerevisiae, as well as their growth without such inoculation, produced wines whose volatile compositions were essentially different from those of wines arising from the use of $S$. cerevisiae to start the fermentation. They also noted that the ratio of isoamyl alcohol to active amyl alcohol and isobutanol to propanol, are in general, characteristic for each yeast. Their results showed that apiculate yeasts are important contributors to the chemical composition and quality of wine. Longo et al. (1992) also showed that dodecanol and tetradecanol production is highly yeast strain characteristic. Mateo et al. (1991) studied the contribution of different yeasts $(C$. valida, Brettanomyces bruxellensis, Rhodotorula aurantica, $H$. uvarum, K. apiculata, Dekkera intermedia, S. cerevisiae var. capensis, S. cerevisiae var. chevalieri, S. cerevisiae var. bayanus and $S$. cerevisiae var. cerevisiae) isolated from musts of Monastrell grapes to the aroma of wine. Their results also clearly showed the variation in higher alcohol production among the different yeasts. Gil et al. (1996) and Herraiz et al. (1990) found a 3 -fold higher production of higher alcohols in wines fermented

\section{TABLE 7}

Higher alcohol formation (mg/L) by Saccharomyces yeast in 3 varieties of grape juice (Rankine, 1967).

\begin{tabular}{|c|c|c|c|c|c|c|c|c|c|}
\hline \multirow{2}{*}{ Yeast } & \multicolumn{3}{|c|}{$\begin{array}{l}\text { Pedro Ximinez } \\
\text { pH } 3.3\end{array}$} & \multicolumn{3}{|c|}{$\begin{array}{l}\text { Tokay } \\
\text { pH } 3.3\end{array}$} & \multicolumn{3}{|c|}{$\begin{array}{l}\text { Ugni blanc } \\
\text { pH } 3.42\end{array}$} \\
\hline & $n$-PrOH & $i$-BuOH & $\mathrm{AmOH}^{*}$ & $n$-PrOH & $i$-BuOH & AmOH & $n$-PrOH & $i-\mathrm{BuOH}$ & AmOH \\
\hline S. fructum & 20 & 11 & 140 & 107 & 9 & 142 & 52 & 8 & 145 \\
\hline S. cerevisiae a & 16 & 23 & 95 & 41 & 14 & 126 & 21 & 15 & 125 \\
\hline S. chevalieri & 12 & 39 & 207 & 26 & 30 & 256 & 10 & 34 & 280 \\
\hline S. cerevisiae b & 56 & 21 & 151 & 170 & 9 & 151 & 92 & 9 & 264 \\
\hline S. oviformis & 18 & 12 & 111 & 38 & 10 & 128 & 16 & 11 & 146 \\
\hline S. cerevisiae c & 13 & 41 & 259 & 25 & 38 & 270 & 14 & 31 & 257 \\
\hline S. cerevisiaed & 13 & 22 & 171 & 24 & 18 & 216 & 18 & 15 & 173 \\
\hline S. bayanus & 9 & 30 & 166 & 19 & 35 & 249 & 11 & 26 & 195 \\
\hline
\end{tabular}


TABLE 8

Variation of higher alcohol concentrations $(\mathrm{mg} / \mathrm{L})$ in wines produced by different yeasts (adapted from Gil et al., 1996)

Pure culture wines ${ }^{a}$

Mixed culture wines ${ }^{\mathrm{b}}$

\begin{tabular}{lcccccccccc} 
& A48 & L22 & T73 & HAN & KLO & M1 & M2 & M3 & M4 & M5 \\
\hline Propanol & 10.1 & 12.1 & 10.0 & 3.7 & 9.7 & 16.8 & 10.5 & 14.5 & 19.2 & 14.1 \\
Isobutyl alcohol & 62.0 & 44.7 & 35.5 & 9.8 & 18.0 & 72.4 & 68.9 & 78.7 & 60.0 & 87.6 \\
Butanol & 2.2 & 2.1 & 1.5 & 0.6 & 1.2 & 2.4 & 3.0 & 2.6 & 3.6 & 3.6 \\
Isoamyl alcohol & 166 & 182 & 202 & 29.5 & 44.7 & 247 & 220 & 253 & 209 & 235 \\
Hexanol & 2.2 & 2.3 & 2.4 & 2.5 & 2.4 & 2.3 & 2.3 & 2.4 & 2.4 & 2.2 \\
Phenethyl alcohol & 19.2 & 26.0 & 38.0 & 12.3 & 7.00 & 39.5 & 33.8 & 44.0 & 34.6 & 28.1 \\
\hline Total & $\mathbf{2 6 1 . 7}$ & $\mathbf{2 6 9 . 2}$ & $\mathbf{2 8 9 . 4}$ & $\mathbf{5 8 . 4}$ & $\mathbf{8 3 . 0}$ & $\mathbf{3 8 0 . 4}$ & $\mathbf{3 3 8 . 5}$ & $\mathbf{3 9 5 . 2}$ & $\mathbf{3 2 8 . 8}$ & $\mathbf{3 7 0 . 6}$
\end{tabular}

${ }^{-\mathrm{a}} \mathrm{A} 48=S$. cerevisiae A48 strain; L22 $=S$. cerevisiae L2226 strain; T73 $=$ S. bayanus T73 strain; HAN $=$

Hanseniaspora uvarum; KLO = Kloeckera apiculata.

${ }^{\mathrm{b}} \mathrm{M} 1=47.5 \% \mathrm{KLO}+47.5 \% \mathrm{HAN}+1 \% \mathrm{~T} 73+4 \% \mathrm{~A} 48 ; \mathrm{M} 2=47.5 \% \mathrm{KLO}+47.5 \% \mathrm{HAN}+1 \% \mathrm{~T} 73+4 \% \mathrm{~L} 22 ;$

$\mathrm{M} 3=5 \% \mathrm{KLO}+5 \% \mathrm{HAN}+89 \% \mathrm{~T} 73+1 \% \mathrm{~A} 48 ; \mathrm{M} 4=5 \% \mathrm{KLO}+5 \% \mathrm{HAN}+5 \% \mathrm{~T} 73+85 \% \mathrm{~L} 22 ; \mathrm{M} 5=5 \%$

$\mathrm{KLO}+5 \% \mathrm{HAN}+90 \% \mathrm{~A} 48$.

with Saccharomyces spp. than in those fermented with pure cultures of apiculate yeasts (Table 8). They also found that wines inoculated with mixed cultures of Saccharomyces spp. and apiculate yeasts produced a higher total concentration of higher alcohols and other aroma compounds than wine inoculated with pure cultures of Saccharomyces spp. Cluster analysis revealed two clearly defined groups of wines (Gil et al., 1996). One major group consisted of the pure culture wines, which in turn was separated into two subgroups, one with Saccharomyces yeasts and the other with apiculate yeasts. The second major group was formed by the mixed culture wines.

Formation of higher alcohols, particularly isobutyl alcohol, increases in aerated musts (Zoecklein et al., 1995). Under oxidative conditions, yeasts with limited fermentative capabilities (Pichia sp., H. anomala, and Candida sp.) produce substantial quantities of fusel alcohols from fermentable sugars (Zoecklein et al., 1995). The effect of aeration is probably stimulated growth and biosynthetic activity of yeast, hence the increase in demand for nitrogenous nutrients. A study done by Mauricio et al. (1997) showed that ethanol, isoamyl alcohol, isobutyl alcohol, phenethyl alcohol and isoamyl, butyl and hexyl acetates were produced in greater concentrations in semi-aerobic conditions, mainly due to cellular growth. 1-Butanol and 1-pentanol were produced in greater levels in anaerobic conditions, when cellular growth was lower.

The higher alcohol, phenethyl alcohol, has the unmistakable odour of roses and is also believed to play a sensory role in the perception of body (Zoecklein et al., 1995). Rankine \& Pocock (1969) found a 4-fold difference among yeasts in the amounts of phenethyl alcohol produced under comparable conditions. It was also shown by Massoutier et al. (1998) that regardless of fermentation temperature, cryotolerant yeasts (S. uvarum) produce 4-fold (216 mg/L compared to $45 \mathrm{mg} / \mathrm{L}$ ) more phenethyl alcohol than mesophilic Saccharomyces yeasts. These cryotolerant yeasts also produced twice as much isobutyl and isoamyl alcohols as the mesophilic yeasts.

\section{Esters}

Esters are a group of volatile compounds that impart a mostly pleasant smell (Table 9). Most esters found in alcoholic beverages are produced by yeasts during fermentation as secondary products of sugar metabolism and constitute one of the largest and most important groups of compounds affecting flavour (Engan, 1974; Peddie, 1990; Fujii et al., 1994). However, a particular aroma property can only rarely be associated with a specific ester (Van Rooyen et al., 1982). The concentration of esters usually found in wine is generally well above their sensory threshold levels and they make up numerically the largest group of aroma compounds in alcoholic beverages (Salo, 1970a, b; Nykänen et al., 1977; De Wet, 1978; Simpson \& Miller, 1984). Thus it is not surprising that some of the descriptors used in sensory evaluation of wine and alcoholic beverages coincide with the associated aroma of these compounds (Maarse \& Visscher, 1989; Etievant, 1991). The fresh, fruity aroma of young wines derives in large part from the presence of the mixture of esters produced during fermentation, which is why it is usually called fermentation aroma/bouquet. Fermentation compounds, especially the acetate esters, are responsible for the desirably fruity, ester-like character of young wines from neutral cultivars such as Chenin blanc and Colombar (Marais \& Pool, 1980).

The esters of alcoholic beverages can be divided into three fractions of different boiling ranges. The first, light fraction consists of compounds eluting before isoamyl-alcohol in a gas chromatogram. The main components are ethyl, isobutyl and isoamyl esters of short chain fatty acids. The middle fraction comprises compounds appearing between ethyl caproate and phenethyl alcohol, and contains ethyl esters of caprylic and capric acids as main components. The third, heavy fraction contains the compounds eluting after phenethyl alcohol. These components include the ethyl esters of tetradecanoic, hexadecanoic and cis-9hexadecanoic acids (Leaute, 1990).

Baumes et al. (1986) divided esters into two groups, based on odour evaluation. The first group he termed apolar. The apolar esters have fairly low detection odour thresholds, and with the 
TABLE 9

Some esters produced by yeast and their concentrations, threshold values and odours in wine (Salo, 1972; Riesen, 1992; Boulton et al., 1995).

\begin{tabular}{|c|c|c|c|}
\hline Compound & $\begin{array}{c}\text { Conc. in wine } \\
(\mathrm{mg} / \mathrm{L})\end{array}$ & Threshold value (mg/L) & Odour \\
\hline Ethyl acetate & & $\begin{array}{c}17.62^{*} \\
12.3\end{array}$ & Varnish, nail polish, fruity \\
\hline Isoamyl acetate & $0.03-8.1$ & $0.26 *$ & Banana, pear \\
\hline 2-Phenethyl acetate & $0.01-4.5$ & & $\begin{array}{l}\text { Rose, honey, fruity, } \\
\text { flowery }\end{array}$ \\
\hline Ethyl isovalerate & $\mathrm{ND}-0.7$ & & Apple, fruity \\
\hline Isobutyl acetate & $0.01-0.8$ & & Banana \\
\hline Ethyl butanoate & $\begin{array}{c}0.01-1.8 \\
0.01-3\end{array}$ & $0.4^{\text {(beer) }}$ & Floral, fruity \\
\hline Ethyl 2-methyl-butanoate & ND - 0.9 & & Strawberry, pineapple \\
\hline \multicolumn{4}{|l|}{ Hexyl acetate } \\
\hline Ethyl hexanoate & Trace -3.4 & 0.08 & Apple, banana, violets \\
\hline Ethyl octanoate & $0.05-3.8$ & $\begin{array}{c}0.58 \\
0.258^{*}\end{array}$ & Pineapple, pear \\
\hline Ethyl decanoate & Trace -2.1 & 0.5 & Floral \\
\hline
\end{tabular}

* Percentage-above-chance-scores of $50 \%$ in grain spirit solutions of $9.4 \%(\mathrm{w} / \mathrm{w})$

exception of ethyl acetate, contribute fruit and flower notes to wine aroma. Apolar esters are present in wine in lesser amounts than polar esters, and include ethyl acetate, isoamyl acetate, ethyl octanoate, ethyl hexanoate, ethyl propanoate, ethyl butanoate and 2-phenethyl acetate. Polar esters have proved to be relatively insignificant contributors to wine aroma, contributing more to the body of a wine. They include 2-ethyl-hydroxypropionate, diethyl succinate, ethyl-4-hydroxybutanoate, diethyl malate, isopentyl-2hydroxypropionate and ethyl-3-hydroxy butanoate. Ethyl hexanoate has an odour reminiscent of apple and violets, ethyl octanoate an odour reminiscent of pineapple and pear, and ethyl decanoate has a floral odour (Boulton et al., 1995). Many esters can be formed, but the most significant ones are acetate esters of higher alcohols: ethyl acetate, isoamyl acetate, isobutyl acetate, ethyl hexanoate and 2-phenylethyl acetate; and ethyl esters of straight-chain, saturated fatty acids: ethyl butanoate, ethyl hexanoate, ethyl octanoate, ethyl decanoate and ethyl dodecanoate (Thurston et al., 1981; Marais, 1990; Fujii et al., 1994). Table 9 lists some of the more prominent esters produced by yeast during fermentation. Ethyl acetate is the main ester occurring in wine. The proportion of the fatty acid ethyl esters transferred from yeast to the medium decreases with increasing chain length: $100 \%$ in the medium for ethyl hexanoate, $54-68 \%$ for ethyl octanoate, 8$17 \%$ for ethyl decanoate; from ethyl dodecanoate $100 \%$ is retained inside the cell (Nykänen et al., 1977).

The volatile character of "acetic nose" is not exclusively the result of acetic acid. Ethyl acetate contributes significantly to this defect, and levels of 150 to $200 \mathrm{mg} / \mathrm{L}$ impart spoilage character to wine (Amerine \& Cruess, 1960). High acetic acid content does not always confer a spoilage character to wine; this depends on the acetic acid to ethyl acetate ratio. Rejection levels determined for ethyl acetate in white and red wines were identified at 170 and $160 \mathrm{mg} / \mathrm{L}$, respectively (Corison et al., 1979).

The valuable contribution of acetates of higher alcohols to wine aroma has been known for some time. These compounds are synthesized during must fermentation in concentrations usually higher than those theoretically to be expected from their hydrolysis/synthesis equilibria. This means that they are hydrolized to a significant degree in the early stages of wine maturation, following kinetic behaviour well described by Ramey \& Ough (1980). Thus, they are particularly important in young wine bouquet, though they still can play a significant role in an aged wine.

Young red table wines of the cultivar Pinotage have a distinct fermentation ("duco") character (Van Wyk et al., 1979). This bouquet is not present in either the Pinotage grapes or must, and is known to be formed during fermentation. Isoamyl acetate, when present in relatively large concentrations, was shown to be the "impact" compound for this typical bouquet. The presence of this bouquet is evidently considered to be within limits a positive quality-enhancing factor. At present, winemakers actively avoid preparing young wines with excessive duco character. During ageing this bouquet gradually decreases in intensity and finally disappears. This change is accompanied by a concurrent decrease in isoamyl acetate concentration.

To determine the contribution of esters to wine aroma, Van der Merwe \& Van Wyk (1981) were able to reproduce the quality and intensity of a dearomatised wine by addition of esters. Shortchain esters produced fruity characters, while longer chain esters were responsible for soap-like characters. Ferreira et al. (1995) 
investigated the roles played by ethyl esters of fatty acids and by acetates of higher alcohols on the aroma of young wines from neutral grape varieties. They found that the roles played by these compounds depends on the type of wine. In white wines their main role was in creating the perception of tree fruit and tropical fruit notes. It has been demonstrated that the former notes are linked to ethyl esters, while the latter are linked mainly to acetates of higher alcohols. In red wines, these compounds did not determine the intensity of fruit aromas, and they only play a modulating role on aroma quality (Ferreira et al., 1995).

There are several factors that influence ester production by yeast during fermentation, such as grape maturity and sugar content (Houtman et al., 1980a, b), the strain used, fermentation temperature (Daudt \& Ough, 1973; Engan, 1974; Piendl \& Geiger, 1980), vinification methods (Herraiz \& Ough, 1993; Gômez et al., 1994), insoluble materials in the grape must (Houtman et al. 1980a, b; Edwards et al., 1985), skin contact time (Falqué \& Fernández, 1996), cultivar, must pH (Marais, 1978) and sulfur dioxide (Daudt \& Ough, 1973; Herraiz et al., 1989, 1990). There are also several factors that influence the concentrations of esters during the ageing process after fermentation. However, although esters are ubiquitous to all wines and brandies, the levels formed are yeast strain dependent (Mateo et al., 1992). Numerous chemical changes also occur in wines during storage and ageing, and these changes may drastically affect aroma and quality. Depending on the storage temperature, the fruity character of young wines can disappear quite rapidly (Marais \& Pool, 1980; Ramey \& Ough, 1980). Thus, all of the above mentioned factors together determine the ester concentration present in the alcoholic beverage. The final concentration of an ester in a wine is dependent on its formation and destruction during the fermentation and ageing process and its distribution between the wine and yeast (Houtman et al., 1980a, b; Marais \& Pool, 1980).

Biosynthesis of esters by yeast: The direct, enzyme-free formation of esters is an equilibrium reaction between an alcohol and an acid, as for example, the formation of ethyl acetate from acetic acid and ethanol $\left(\mathrm{CH}_{3} \mathrm{COOH}+\mathrm{C}_{2} \mathrm{H}_{5} \mathrm{OH} \leftrightarrow \mathrm{CH}_{3} \mathrm{COOC}_{2} \mathrm{H}_{5}+\right.$ $\mathrm{H}_{2} \mathrm{O}$ ) (Engan, 1974). Although a great number of alcohols and acids are formed during fermentation, some are present in the raw material, e.g. grapes. All of the alcohols and acids may react to form esters and therefore the theoretical number of esters in wine is very large. Direct ester formation is, however, too slow to account for the ester concentrations found in alcoholic beverages. According to Nordström (1964a), the formation of ethyl acetate during fermentation proceeds according to the following reaction: $\mathrm{CH}_{3} \mathrm{CO}-\mathrm{SCoA}+\mathrm{C}_{2} \mathrm{H}_{5} \mathrm{OH} \leftrightarrow \mathrm{CH}_{3} \mathrm{COOC}_{2} \mathrm{H}_{5}+\mathrm{CoASH}$. Alcohols become esterified by reacting with fatty acids which have undergone a previous activation by combining with coenzyme A (CoASH). Although acetyl-CoA can be formed by the oxidative decarboxylation of pyruvate, most of the other acylCoA compounds come from acylation of CoASH by the action of acyl-CoA synthetase. It is in these activated forms that acyl-CoA compounds can act as the acyl donor. As a result of the need for activation, ester synthesis is an energy-requiring process (Fig. 4). Furthermore, in ester as well as in fatty acid synthesis, the lengthening of the carbon chain of the acid moiety occurs so that malonyl-CoA binds with acyl-CoA in the enzyme complex, bringing two more carbon atoms into the chain of the acid. In the final step an ester is produced in the presence of alcohol, whereas when water is present the result is a free fatty acid. Acetate esters are synthesized by an enzyme called alcohol acetyltransferase, which uses as substrates an alcohol and acetyl-CoA (Peddie, 1990). Acetyl-CoA is formed partly by activation of acetic acid (requiring ATP) and partly by oxidative decarboxylation of pyruvate (requiring lipoic acid and thiamine pyrophosphate) (Piendl \& Geiger, 1980). It is important to stress the central role played by acetyl-CoA in ester synthesis, since it is involved in many other reactions within the yeast cell (Fig. 5); e.g. lipid biosynthesis, amino acid biosynthesis, fatty acid biosynthesis and the TCA cycle (Nordström, 1964c; Piendl \& Geiger, 1980; Yoshioka \& Hashimoto, 1983). Factors which govern the anabolism and catabolism of this compound are crucial for ester production (Peddie, 1990; Dufour \& Malcorps, 1994). In a general sense, acetyl-CoA can react with higher alcohols to yield the acetate esters, and acyl-CoA compounds can react with ethanol to yield the ethanol esters. Since acetyl-CoA/acetic acid and ethanol are the most abundant acids and alcohols present in the fermentation, ethyl acetate is normally the most abundant ester. However, if effective analytical techniques are used, almost every combination of acyl-CoA and alcohol can be detected as esters in the fermentation product.

Thurston et al. $(1981,1982)$ reported a large increase in the specific rate of ester production in the latter half of fermentation, which is concurrent with the cessation of lipid synthesis. This, they concluded, is due to the transient increase of available acetyl-CoA, since in the beginning of fermentation ester synthesis is very slow due to the high metabolic demand for acetyl-CoA for yeast growth (Yoshioka \& Hashimoto, 1983). At this point oxygen and acetyl-CoA are rapidly consumed for the production of unsaturated fatty acids and sterols. After monitoring the formation of medium-chain fatty acids and related ethyl esters, Bardi et al. (1998) also proposed a model in which ester synthesis is a consequence of the arrest of lipid biosynthesis resulting from a lack of oxygen. Under these conditions, an excess of acyl$\mathrm{CoA}$ is produced, and acyl esters are formed as secondary products of reactions aimed at recovering free CoA. In contrast, Dufour \& Malcorps (1994) suggested that ester synthesis is not inhibited by unsaturated fatty acids or oxygen, but is rather modulated by a repression-induction of enzyme synthesis or processing. Data presented by Calderbank \& Hammond (1994) support the view that precursor alcohol concentration is very important for ester synthesis and that many of the influences of fermentation conditions on ester synthesis are related to alcohol substrate availability. Because ethanol dominates among the alcohols and acetic acid among the volatile acids, most of the esters will be either ethyl esters or acetates. Only minor amounts of other esters are to be expected, as the corresponding alcohols are present in rather low quantities. The similar behaviour of all examined ester synthesizing enzymes points to the involvement of the same enzymatic system and to the existence of a common regulatory mechanism.

The physiological driving force for ester production remains obscure. Esters could simply be overspill products from sugar metabolism during fermentation and may be of no advantage to the.yeast cell. Rainbow (1970) suggested that fatty acids with a chain length between $\mathrm{C} 8-\mathrm{C} 14$ are toxic to the yeast, exhibit 


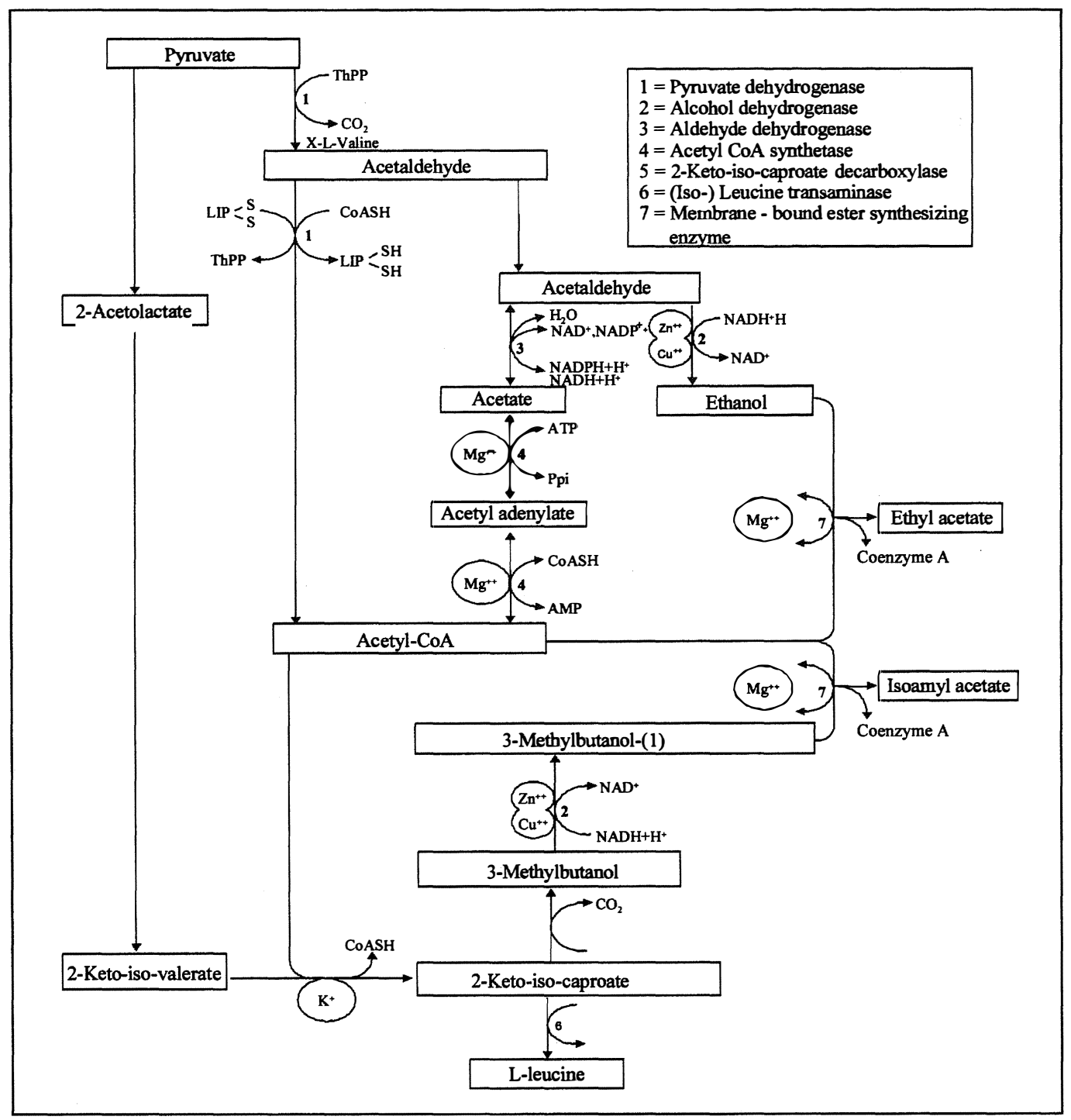

FIGURE 4

Schematic representation of the metabolic regulation of the formation of ethyl acetate and isoamyl acetate (Piendl \& Geiger, 1980).

strong anti-microbial activity and, if unsaturated, intensify the effect. Esters may be formed to remove these toxic fatty acids from the yeast cell (Nordström, 1962, 1964b). Esters of shorter chain fatty acids ( $\mathrm{C} 2$ - $\mathrm{C} 6$ ) would be produced by the same detoxification process. As there are several enzymes involved in the synthesis of esters, this suggests the possibility of different metabolic roles for long-chain and medium-chain alcohol acetylation, and for esterification of long-chain and medium-chain fatty acids with ethanol and ethyl acetate synthesis (Dufour \& Malcorps, 1994). A possible role of ethyl acetate synthesis could be to regenerate free coenzyme A from acetyl-CoA without releasing acetic acid. The physiological role of medium-chain aliphatic ester synthesis (isoamyl acetate, ethyl caproate) in yeast remains undetermined. Another reason for ester formation could be to reduce the acetyl charge, as it is essential for the yeast cell to maintain a balance between acetyl-CoA and $\mathrm{CoASH}$. Therefore, yeasts synthesize esters to correct any imbalance of the CoA: acetyl-CoA ratio caused by the cessation of the lipid synthesis pathway through fermentation (Thurston et al., 1981, 1982; Bardi et al., 1998). In contrast, preliminary evidence by Calderbank \& Hammond (1994) on in vitro alcohol acetyl transferase (AAT) activity (the enzyme involved in ester synthesis) suggests that this enzyme may be primarily responsible for triglyceride or phospholipid synthesis and that ester synthesis is a minor function for it.

Yeast strain effect on ester formation: Particular attention has also been given to ester formation by different yeasts. According to Nykänen (1986), Sponholz et al. (1974) showed that H. anomala and $C$. krusei yeasts have been found to produce more ethyl acetate than do S. cerevisiae, S. pombe and Pichia membranaefaciens. In another study Pichia fermentans produced greater amounts of ethyl acetate than two other $S$. cerevisiae yeast strains, Rankine and Montrachet, which formed the normal amount of ethyl acetate (Ough et al., 1968). On the other hand, of these five 


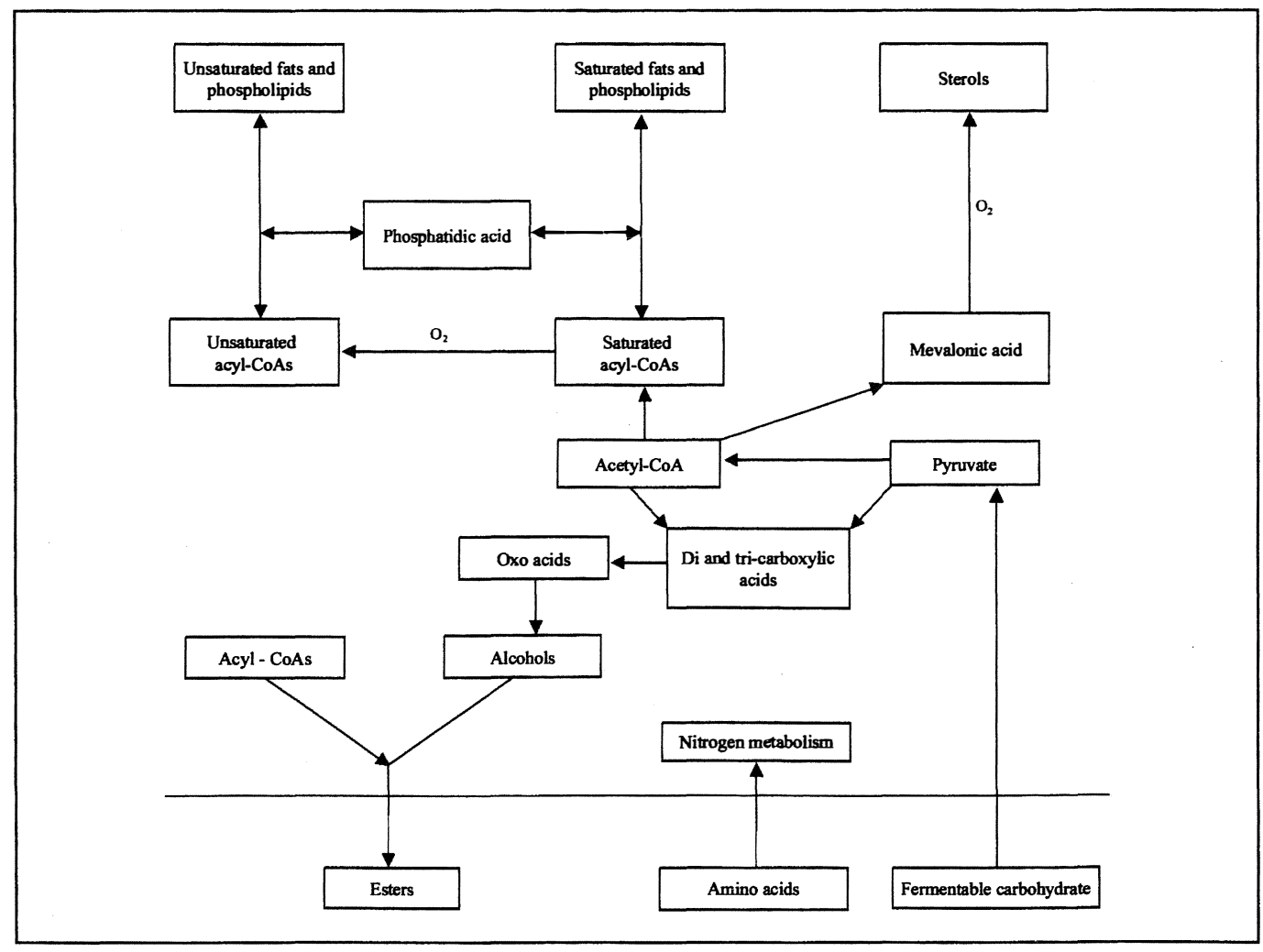

FIGURE 5

Metabolic pathways involved in ester production (García et al., 1994).

yeasts, $H$. anomala and $C$. krusei formed the lowest amounts of octanoic-, decanoic-, and lauric acid ethyl esters. According to Suomalainen \& Lehtonen (1979) Rhodotorula yeast increases the formation of isoamyl acetate. They have also shown that $H$. anomala and $C$. krusei yeasts produce less esters than, for example, S. pombe. Nykänen \& Nykänen (1977) also investigated the ability of different yeasts to produce the acetates of isopenthyl and phenethyl alcohol and ethyl esters of the C6-C12 fatty acids in semi-aerobic sugar fermentations. They performed the fermentations with 57 strains of $S$. cerevisiae and three strains of $S$. uvarum; the strains of $S$. cerevisiae were found to produce more isopenthyl acetate, ethyl hexanoate, ethyl octanoate, ethyl decanoate and phenethyl acetate than the S. uvarum yeasts. A higher proportion of the esters formed appeared to remain in the cells of $S$. uvarum strains than in the cells of $S$. cerevisiae. Suomalainen \& Lehtonen (1979) also showed that S. cerevisiae produces significantly more isoamyl acetate, ethyl caproate, ethyl caprylate and ethyl caprate than does $S$. uvarum.

Lema et al. (1996) studied the dynamics of Saccharomyces and non-Saccharomyces populations during alcoholic fermentation of Albariño musts from two enological subzones located in Galicia (northwest Spain). They conducted sixteen microvinifications (eight in each must) with five indigenous $S$. cerevisiae strains, two commercial active dry yeast strains and the corresponding spontaneous fermentation. The concentration levels of the compounds analyzed in the wines depended not only on the S. cerevisiae strain used in the winemaking, but also on its predomi- nance during alcoholic fermentation, which in turn was directly related to the initial concentration of yeast inoculated into the must and to the origin of the yeast (Lema et al., 1996). A predominance of the $S$. cerevisiae strain inoculated during the fermentative process, along with a notable growth rate of the nonSaccharomyces populations in the first days of fermentation, significantly contributed to the production of volatile compounds related to the good aromatic quality of Albariño wines. The indigenous $S$. cerevisiae strain from the "O Rosal" subzone winery inoculated into the must originating from that winery produced higher quantities of ethyl esters, higher alcohol acetates and fatty acids in the resulting wine. This was probably due to its better adaptation to the chemical and microbiological characteristics of the must from this winery (Lema et al., 1996).

Fourteen pure-culture wine yeasts were found to produce white wines with significantly different ester concentrations (Soles et $a l .$, 1982). The esters quantified, by glass capillary gas chromatography, were isoamyl acetate (including active amyl acetate), ethyl hexanoate, hexyl acetate, ethyl octanoate, 2phenylethyl acetate and ethyl decanoate. Wine fermented by the S. cerevisiae strain Rankine no. 350 was found to contain statistically more of these six esters in total than any of the other yeast fermentations. The S. cerevisiae Rankine no. 350 strain produced significantly more isoamyl acetate than the other yeasts studied. The lowest production level of isoamyl acetate was by the Saccharomyces fermentati Flor strain (Soles et al., 1982). Wine fermented by the $S$. fermentati Flor strain contained significantly 
more ethyl hexanoate than wine fermented by all the other yeasts except Rankine no. 350 and S. bayanus, a Champagne strain from the Institute Pasteur. S. bayanus strain CaliforniaChampagne, S. cerevisiae Rankine no. 350, Saccharomyces bailii and an isoleucine-deficient mutant of $S$. cerevisiae produced significantly greater amounts of hexyl acetate than the other yeasts tested except the $S$. cerevisiae Geisenheim strain (Soles et al., 1982). The $S$. bayanus California-Champagne strain produced a significantly higher amount of 2-phenylethyl acetate than eight other yeasts, while the $S$. bayanus Institute Pasteur strain produced wine with more of this ester than seven other yeasts. Ethyl decanoate was produced in significantly different amounts by the yeasts. The $S$. bayanus California-Champagne strain produced significantly higher amounts of ethyl decanoate than nine other yeasts.

In another study Delteil \& Jarry (1992) studied the characteristic effects of two commercial yeast strains on Chardonnay wine volatiles. Chardonnay wines fermented with K1M (ICV K1 Marquée, ADWY, batch no: 4254, Lallemand, Canada) contained higher concentrations of isoamyl acetate, ethyl laurate and total esters, and these concentrations were mainly must independent. Chardonnay wines fermented with D47 (ICV D47, ADWY, batch no: 8054, Lallemand, Canada) contained higher concentrations of ethyl caproate and ethyl caprylate, but these concentrations were highly must-dependent. The two major styles of young commercial Chardonnay wines fermented with these two strains reflected differences; high aroma intensities with fresh banana and citrus characters for $\mathrm{K} 1 \mathrm{M}$ wines (due to the higher acetate ester levels and higher and better varietal expression), and pineapple and spicy characters for D47 wines due to the lower acetate ester levels (Table 10) (Delteil \& Jarry, 1992).

Aroma compounds of wines fermented from sterile grape musts of the Monastrell variety inoculated with pure and mixed cultures of apiculate and Saccharomyces yeasts were isolated and analyzed (Gil et al., 1996). In wines fermented only with apiculates (H. uvarum and $K$. apiculata) which had an elevated amount of residual sugars, ester amounts were detected similar to those found in the wines inoculated with Saccharomyces species. Clearly, apiculate yeasts can affect the chemical composition of wines and thus impact on quality (Gil et al., 1996).
The evolution of the cell and must contents of three mediumchain fatty acids (C6, C8, and $\mathrm{C} 10)$ and their ethyl esters during fermentation with $S$. cerevisiae strains cerevisiae, bayanus and capensis were studied (Zea et al., 1994). The first is a fermentative yeast; the last two are flor film yeasts. Maximum ester concentrations in the cells were attained after 48-72 hours of fermentation. Secretion during this period was quite active, particularly with the flor film yeasts, and musts fermented by these yeasts featured higher maximal ester concentrations than those fermented by $S$. cerevisiae strain cerevisiae. In the musts, ethyl octanoate and ethyl decanoate also reached a peak at this point but ethyl hexanoate peaked only after 10 days. After 134 days, $S$. cerevisiae strain capensis formed a thick flor film, the strain bayanus developed a thin film, and the strain cerevisiae formed no film, with non-viable cells accumulating in the bottom of the fermenter. At this point the ethyl ester contents tended to decrease, with the exception of ethyl decanoate, in the fermentations carried out by $S$. cerevisiae strains cerevisiae and bayanus (Zea et al., 1994). The decrease of these compounds in all wines at the end of this study cannot be attributed only to the flor film yeasts' growth, although this growth induced a greater decrease relative to the fermentative strain in the early ageing period (134 days). The esters already formed and secreted into the wine must disappear due to their chemical hydrolysis at the physical $\mathrm{pH}$ of wine, as pointed out by Ramey \& Ough (1980), or by hydrolytic processes carried out by enzymes of the grapes and yeasts themselves.

Sixteen ethyl esters of amino acids have been identified in wines and sherries (Heresztyn, 1984; Herraiz \& Ough, 1992). These compounds were found in concentrations of up to $58 \mathrm{mg} / \mathrm{L}$ in the wines analyzed; the amounts found indicate that these esters contribute significantly to the pool of basic compounds in wines. Herraiz \& Ough (1993) showed that the amino acid ethyl esters are formed during the alcoholic fermentation by yeasts, mainly in the second half of the fermentation, when the concentration of ethanol in the medium was high. It should be expected that high levels of intracellular ethanol in the yeast may increase the formation of ethyl esters formed from amino acids and later liberate them to the surrounding medium. The level of these compounds appeared to increase during yeast autolysis. Some differ-

\section{TABLE 10}

Differences in ester production by yeast strains (Delteil \& Jarry, 1992).

\begin{tabular}{lcc}
\hline Compound (mg/L) & ICV K1M & ICV D47 \\
\hline Isoamyl acetate & 16.45 & 9.00 \\
Ethyl dodecanoate & 0.09 & 0.05 \\
Hexyl acetate & 0.33 & 0.53 \\
Ethyl hexanoate & 1.13 & 1.38 \\
Ethyl octanoate & 1.54 & 1.85 \\
Ethyl decanoate & 0.6 & 0.5 \\
Diethyl succinate & 0.33 & 0.41 \\
\hline Total esters & $\mathbf{2 3 . 6 3}$ & $\mathbf{1 4 . 2 6}$ \\
\hline
\end{tabular}


ences were also found between the two yeasts used.

Ethyl esters of alanine, valine, leucine, isoleucine and proline were identified in all the wines studied. Glycine-, $\gamma$-aminobutyric-, threonine-, serine-, phenylalanine-, tyrosine- and lysineethyl ester were identified in almost all samples, whereas methionine-ethyl ester was identified in eight wines. Two diethyl esters, aspartic acid- and glutamic acid-, were detected only in sherries. Proline ethyl ester was found in the highest amounts; the other amino acid esters found in excess of $1 \mathrm{mg} / \mathrm{L}$ were alanine-, glycine- and $\gamma$-aminobutyric-ethyl ester. Cysteine ethyl ester was not detected (Herraiz \& Ough, 1992).

\section{Carbonyl compounds}

Short chain, volatile aldehydes are important to the flavour of a number of foods and beverages, including wine, contributing flavour characteristics ranging from "apple-like" to "citrus-like" to "nutty" depending on the chemical structure (Table 11). Together with the keto-acids, the short-chain aliphatic aldehydes are the key compounds in the biochemical reaction involving the production of higher alcohols from amino acids and sugars by yeast. They are formed in the yeast cell and then transferred to the medium (Nykänen et al., 1977). Because of their low sensory threshold values, aldehydes are important to the aroma and bouquet of wine; among these, acetaldehyde is the major component, constituting more than $90 \%$ of the total aldehyde content in wines and spirits (Nykänen et al., 1977).

Acetaldehyde is a normal product of alcoholic fermentation and its amount in wine can vary from $10 \mathrm{mg} / \mathrm{L}$ up to $300 \mathrm{mg} / \mathrm{L}$ (Schreier, 1979), with a sensory threshold value of $100 \mathrm{mg} / \mathrm{L}$ (Berg et al., 1955). In white wines acetaldehyde is regarded as an indicator of the wine oxidation state, whereas in red wines it should be present in amounts up to $100 \mathrm{mg} / \mathrm{L}$. Sherry and Tokay wines contain relatively high amounts of acetaldehyde, due to their production under oxidative conditions.

Normally wines contain $0.2-0.3 \mathrm{mg} / \mathrm{L}$ of diacetyl produced by yeast metabolism. This compound with a buttery aroma becomes objectionable at 1-4 mg/L. Such high values will be due to the growth of lactic acid bacteria (Sponholz, 1993); therefore, diacetyl production by bacteria is far more important than the small amounts which might be produced by yeast during vinification.

Mousiness in wines is caused by the nitrogenous carbonyl compounds 2-acetyl-3,4,5,6-tetrahydropyridine, 2-acetyl1,2,5,6-tetrahydropyridine and 2-ethyl-3,4,5,6-tetrahydropyridine (Heresztyn, 1986; Rapp, 1998). Lactobacillus bacteria and yeast from the genus Brettanomyces are usually responsible for this odour. These compounds are produced by Brettanomyces yeasts from the metabolism of lysine.

Biosynthesis of carbonyl compounds by yeast: The precursors of aldehydes, the 2-keto acids, are formed as intermediates in both the anabolic and catabolic formation of amino acids or higher alcohols. Conditions which favour higher-alcohol production also favour the formation of small quantities of aldehydes (Berry, 1995). These may be secreted but can be reabsorbed and reduced by yeast to the corresponding alcohol during the later stages of the fermentation. Acetaldehyde is an intermediary product formed from pyruvate and is a precursor for acetate, acetoin and ethanol. Oxidation of alcohols, Strecker degradation of amino acids and autoxidation of fatty acids may also produce aldehydes in alcoholic beverages. Acetaldehyde concentrations reach a maximum at the point in fermentation when the most rapid carbohydrate dissimilation takes place. It falls to a low level at the end of fermentation, and thereafter slowly increases again. The

\section{TABLE 11}

Some carbonyl compounds produced by yeast and their concentrations, threshold values and odours in wine (Schreier, 1979; Darriet $e t$ al., 1995; Ribéreau-Gayon et al., 1998; Ebeler \& Spalding, 1999).

\begin{tabular}{lccl}
\hline Compound & $\begin{array}{c}\text { Conc. in wine } \\
(\mathbf{m g} / \mathbf{L})\end{array}$ & $\begin{array}{c}\text { Threshold } \\
(\mathbf{m g} / \mathbf{L})\end{array}$ & \multicolumn{1}{c}{ Odour } \\
\hline Acetaldehyde & $10-300$ & 100 & $\begin{array}{l}\text { Sour, green apple } \\
\text { Bitter almond }\end{array}$ \\
Benzaldehyde & $\begin{array}{c}0.3 \times 10^{2}-4.1 \\
\text { Traces }\end{array}$ & & $\begin{array}{l}\text { Pungent } \\
\text { Butanal }\end{array}$ \\
Diacetyl & $0.05-5$ & $0.15^{\dagger}$ & Buttery \\
& Traces & $2-5^{*}$ & \\
Propanal & Traces & & $\begin{array}{l}\text { Similar to acetaldehyde } \\
\text { Slightly apple like } \\
\text { Isobutanal }\end{array}$ \\
Pentanal & Traces & & $\begin{array}{l}\text { Cocoa, coffee-like, slightly fruity, choking } \\
\text { at high levels } \\
\text { Warm, herbaceous, slightly fruity, nut-like, } \\
\text { acrid at high levels } \\
\text { Isovaleraldehyde }\end{array}$ \\
Traces & & Mousy taint \\
2-acetyltetrahydropyridine & Traces & $1.6 \times 10^{-3}$ &
\end{tabular}


autoxidation of vicinal di- and tri-hydroxy phenols also present in the wine leads to the formation of hydrogen peroxide, a strong oxidant, which further initiates a number of oxidation reactions involving oxidation of ethanol to acetaldehyde (Rosi et al., 1989; Romano et al., 1994).

The formation of acetaldehyde also depends on various fermentation conditions. These include extreme aerobic growth conditions (Bennetzen \& Hall, 1982), the medium composition (Denis et al., 1983), and the nature of insoluble materials used to clarify musts (Delfini et al., 1993). The amount of acetaldehyde present in wines increases during ageing from oxidation of ethyl alcohol, the activity of film yeasts, or aeration. The use of high concentrations of sulfur dioxide in grape must fermentation causes a considerable increase in acetaldehyde levels formed by the yeast cell. Cassalone et al. (1992) found that sulfite-resistant mutants of $S$. cerevisiae accumulate much more acetaldehyde in the medium than does the parental strain.

Fermentation temperature may affect acetaldehyde content, but the reports are mixed. Amerine \& Ough (1980) reported that fermentation temperature does not have a significant affect on the final total aldehyde content, whereas other researchers found that aldehyde content increased with increasing fermentation temperature. In a study performed by Romano et al. (1994), a fermentation temperature of $30^{\circ} \mathrm{C}$ considerably increased the amount of acetaldehyde produced

The decarboxylation of pyruvic acid, and complexing with the coenzyme thiamine pyrophosphate, produces a product called active acetaldehyde. The latter further combines with another molecule of pyruvic acid to give $\alpha$-acetolactic acid. Diacetyl is then formed via the oxidative decarboxylation of $\alpha$-keto-acetolactate (Boulton et al., 1995). The final concentration in the beverage is determined by the balance between the rate of formation and the rate of degradation. In the later stages of the fermentation, diacetyl can be metabolized by the yeast to acetoin and butane2,3-dione (Berry, 1995).

Yeast strain effect on aldehyde content: The total aldehyde content varies with the type of yeast strain used. In assays performed by Then \& Radler (1971) with 300 different yeasts, the aldehyde content was found to vary from 6 to $190 \mathrm{mg} / \mathrm{L}$. Other data indicate that $S$. cerevisiae strains produce relatively high levels (from 50 to $120 \mathrm{mg} / \mathrm{L}$ ), whereas other wine yeasts, such as $K$. apiculata, C. krusei, C. stellata, $H$. anomala and $M$. pulcherima, produce low levels (from non detectable amounts to $40 \mathrm{mg} / \mathrm{L}$ ) of acetaldehyde (Fleet \& Heard, 1993). Romano et al. (1994) divided 86 $S$. cerevisiae wine strains into groups producing low, medium and high amounts of acetaldehyde. The low and high phenotypes also differed considerably in the production of acetic acid, acetoin and higher alcohols. Wines obtained with the low acetaldehyde producers had traces of acetoin, lower amounts of acetic acid $(<500$ $\mathrm{mg} / \mathrm{L})$, and a higher total content of higher alcohols ( $>300 \mathrm{mg} / \mathrm{L})$. Wines obtained with the high producers showed a different pattern, containing detectable amounts of acetoin, elevated amounts of acetic acid (528 to $1185 \mathrm{mg} / \mathrm{L}$ ), and a lower content of higher alcohols (256 to $270 \mathrm{mg} / \mathrm{L}$ ). Longo et al. (1992) also found variations in the production of acetaldehyde from 13.1 to $24.3 \mathrm{mg} / \mathrm{L}$ among 14 strains of $S$. cerevisiae.

Yeasts are able to utilize benzaldehyde in the presence of glucose.
Some strains of $S$. cerevisiae and $S$. japonicus can transform benzaldehyde into benzyl alcohol and benzoic acid (Nykänen, 1986). Delfini et al. (1991) found that Schizosaccharomyces and Zygosaccharomyces were strongest in producing benzaldehyde (maximal amount found was $1200 \mathrm{mg} / \mathrm{L}$ ) and benzyl alcohol [maximally $523 \mathrm{mg} / \mathrm{L}$ in a synthetic nutritive medium (MNS) with 10 ppm of benzyl alcohol, benzoic acid, 4-hydroxybenzoic acid and phenylacetic acid added].

Zygosaccharomyces was also noted to be the most effective in the production of benzoic acid (maximally $536 \mathrm{mg} / \mathrm{L}$ ), followed by Saccharomyces, Cryptococcus, Kloeckera and Torulaspora. None of the strains tested were able to accumulate benzaldehyde in this particular medium. Delfini et al. (1991) also verified that yeasts can be an exogenous source of the benzyl alcohol oxidizing enzyme in grape musts and wines. Wine yeast strains of Saccharomyces spp., Zygosaccharomyces spp. and Schizosaccharomyces spp. fermenting in MNS medium containing $150 \mathrm{~g} / \mathrm{L}$ glucose, with benzyl alcohol added, transformed the latter into benzoic acid, but not into benzaldehyde, only when glucose was disappearing. No difference was observed between anaerobic and aerobic fermentation conditions. A catabolic repression by glucose was thought to be highly likely, as the uptake of benzyl alcohol was rapid in fermentation assays in the presence of only $10 \mathrm{~g} / \mathrm{L}$ glucose, and in assimilation assays performed in yeast nitrogen base broth with assimilable carbon compounds added. From an oenological point of view, it is thus important to note that $S$. cerevisiae can utilize benzyl alcohol in grape musts or in wines when it has consumed large amounts of glucose, or while it is utilizing substances with metabolic pathways different from those of glucose. Benzyl alcohol is converted into benzoic acid and no benzaldehyde is formed. Thus catabolic repression of this transformation by glucose also appears likely.

\section{Volatile phenols}

Phenolic substances can be very important to the taste, colour and odour of wines (Dubois, 1983). Glycosidic combinations of 4vinylguiacol, 4-vinylphenol and eugenol may exist in certain grape varieties (Singleton \& Esau, 1969). Acetovanillone, ethyl vanillate and methyl vanillate are described as having a vanilla and spicy character. Instead of directly contributing to the varietal aroma of grapes, fruit phenolics appear to be more important as a source of hydroxycinnamic acid esters. In this regard, coumaric and ferulic acid esters are particularly important, as they can be transformed into volatile phenols during fermentation. Vinylphenols (4-vinylguiacol, 4-vinylphenol) in white wines and ethylphenols (4-ethylguiacol, 4-ethylphenol) in red wines are quantitively the most significant volatile phenols identified as classic components of wine aroma (Singleton \& Esau, 1969; Etievant, 1981; Chatonnet et al., 1997). They appear at concentrations from 0 to $6047 \mu \mathrm{g} / \mathrm{L}$ in wines and can give phenolic off aromas/odours often described as animal, stable, horse sweat, medical, "elastoplast" when present above their threshold levels (Table 12). The phenolic off odour of red wines most often develops during ageing and especially in wines stored in old barrels and seldom racked (Chatonnet et al., 1992; Chatonnet et al., 1993). Brettanomyces/Dekkera intermedius is the yeast species most frequently identified (95\%) in Bordeaux red wines with phenolic off-odours (Chatonnet et al., 1992); Brettanomyces lam- 
TABLE 12

Some vinyl and ethyl phenols produced by yeast and their concentrations, threshold values and odours in wine (Chatonnet et al., 1992, 1993; Rapp, 1998).

\begin{tabular}{lcccl}
\hline Compound & $\begin{array}{c}\text { Conc. in } \\
\text { wine }(\mu \mathrm{g} / \mathrm{L})\end{array}$ & $\begin{array}{c}\text { Threshold value } \\
\text { white wine }(\mu \mathrm{g} / \mathrm{L})\end{array}$ & $\begin{array}{c}\text { Threshold value } \\
\text { red wine }(\mu \mathrm{g} / \mathrm{L})\end{array}$ & Odour \\
\hline 4-Vinylphenol & $0-1150$ & 770 & & $\begin{array}{l}\text { Pharmaceutical, } \\
\text { elastoplast, gouache }\end{array}$ \\
4-Vinylguiacol & $0-496$ & 440 & $\begin{array}{l}\text { Smoky, vanilla, } \\
\text { clovelike }\end{array}$
\end{tabular}

4-Vinyl guaiacol +

4-Vinylphenol [1:1]

\section{4-Ethylphenol}

4-Ethylguiacol

0-6047

0-1561

4-Ethylphenol + 4

ethylguiacol [10:1]
752

605

110

\author{
Wet horse \\ Smoky, vanilla, \\ clovelike
}

bicus is much less common.

The derivatives 4-ethylguaiacol and 4-vinylguaiacol could add smoky, vanilla and clovelike notes to wine (Singleton \& Esau, 1969). Beyond a certain concentration, vinylphenols may be responsible for certain sensory faults in wines, commonly referred to as "phenolic" or "pharmaceutical" taints. 4Vinylphenol is principally responsible for this fault in white wine, to which it confers "heavy", "phenolic" and "medicinal" odours resembling the datura flower, "elastoplast" and gouache. Its presence is always undesirable, even at concentrations lower than its perception threshold, since it masks the fruity nuance of white wines (Dubois, 1983; Chatonnet et al., 1992). It has also been shown that although $500 \mu \mathrm{g} / \mathrm{L}$ 4-ethylphenol, spiked to a faultless neutral wine resulted in medicinal, horse sweat, leathery aromas, $50 \mu \mathrm{g} / \mathrm{L}$ spiked to the same wine already changed the sensory evaluation of the wine. However, this is not the case with 4-vinylguiacol. Despite having a higher limit preference threshold, this molecule can play an important role in the varietal expression of certain grape varieties, such as Gewürztraminer. Nevertheless, the two compounds are always present simultaneously (Dubois, 1983). Concentrations of more than $770 \mu \mathrm{g} / \mathrm{L}$ of a mixture of 4vinylguaiacol/4-vinylphenol (1:1) in white wines can be responsible for heavy "pharmaceutical" odours reminiscent of "elastoplast" (Chatonnet et al., 1993). Consequently, the quality of white wine is depreciated, in most cases, by concentrations of total vinylphenols above $725 \mu \mathrm{g} / \mathrm{L}$ ( $\sum$ vinylphenols/ Limit threshold $>$ 1) (Chatonnet et al., 1992). Over $425 \mu \mathrm{g} / \mathrm{L}$ of a 1:10 blend of 4ethylguaiacol/4-ethylphenol in red wines results in animal, barnyard or stable off odours (Chatonnet et al., 1990).

Biosynthesis of volatile phenols by yeast: Vinyl- and ethylphenols result from the microbiological transformation of trans ferulic and trans-p-coumaric acids, the nonvolatile, odourless precursors present in all wines. It was always believed that these compounds were formed due to the development of lactic acid bacteria in wines. Certain lactic acid bacteria can decarboxylate the cinnamic acids and in some cases reduce the vinylphenols to the corresponding ethylphenols (Chatonnet et al., 1992; Cavin et al., 1993). Chatonnet et al. (1995) showed that the quantities likely to be formed by these lactic acid bacteria are relatively low by comparison to the quantities easily detected in wines judged to be "phenolic". Chatonnet et al. (1997) have recently shown that concentrations above $1 \mathrm{~g} / \mathrm{L}$ of procyanidins significantly inhibited the ability of lactic acid bacteria in general and Lactobacillus plantarum in particular to form ethylphenols. Their results led to the definitive conclusion that contaminating yeasts from the genus Brettanomyces/Dekkera sp. were responsible for the development of the "phenolic" character in red wines. It was also shown that polyphenolic compounds found in red wines did not affect the ability of $B$. bruxellensis to synthesize volatile phenols. Once malolactic and alcoholic fermentation are completed, these yeasts grow easily on traces of residual sugars. Only careful hygiene and proper sulfuring of wines and containers can prevent the development of these undesirable yeasts. Furthermore, the presence of tannins in red wine has no influence on synthesis of volatile phenols by $B$. bruxellensis, as opposed to lactic acid bacteria or $S$. cerevisiae.

Certain yeast strains responsible for the alcoholic fermentation of beer and wine, as well as bacteria from various media, are capable of forming vinylphenols such as 4-vinylphenol or 4vinylguiacol (Goodey \& Tubb, 1982). In the case of yeasts, the synthesis of vinylphenols requires a non-oxidative decarboxylation of the phenolic acids (Gramatica et al., 1982). Volatile phenol synthesis by yeast depends on the nature of the strain and on the presence of certain polyphenolic inhibitors (Chatonnet et al., 1993).

Chatonnet et al. (1993) showed that S. cerevisiae decarboxylates only the cinnamic acids (phenyl-propenoic) into volatile phenols (Fig. 6a). Among the cinnamic acids present in the grape, only ferulic and $p$-coumaric acids can be transformed into 4vinylguiacol and 4-vinylphenol, respectively. The enzyme responsible for this transformation appears to have a greater affinity for $p$-coumarate than for ferulate. The $S$. cerevisiae 
A

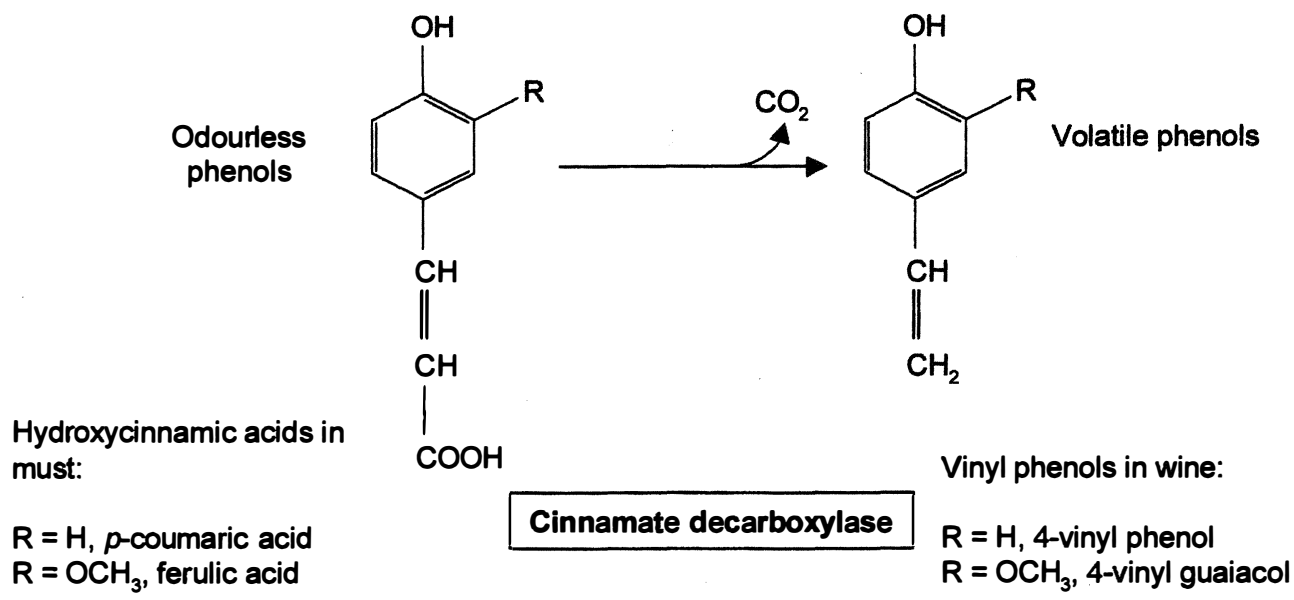

B

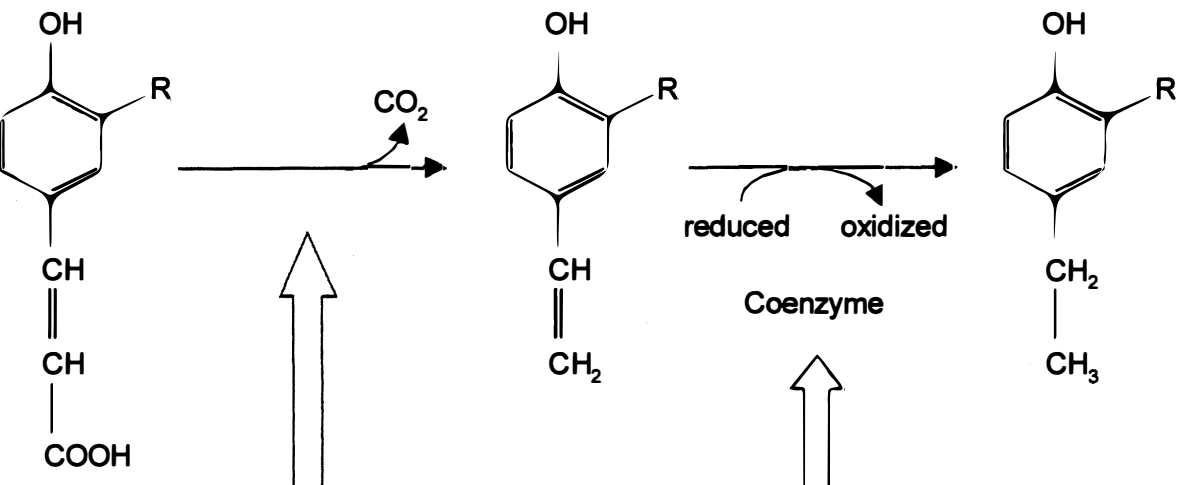

Cinnamate decarboxylase

Vinyl-phenol reductase

$\mathrm{R}=\mathrm{H}$, p-coumaric acid - 4-vinyl and 4-ethyl phenol

$\mathrm{R}=\mathrm{OCH}_{3}$, ferulic acid - 4-vinyl and 4-ethyl guaiacol

FIGURE 6

A) Decarboxylation of phenolic acids by S. cerevisiae during the alcoholic fermentation. B) Enzymatic mechanism for the production of ethyl phenols by Brettanomyces sp. (Ribéreau-Gayon, et al. 1998).

strains they studied were unable to decarboxylate cinnamic acid to form vinylbenzene (styrene). They concluded that the decarboxylase activity of $S$. cerevisiae is therefore a cinnamate decarboxylase. This decarboxylation of the cinnamic acids is stereospecific and occurs only with the trans $(\mathrm{E})$ isomer, generally the form most commonly found in nature. The cinnamate decarboxylase of S. cerevisiae is strictly intracellular and has an optimum $\mathrm{pH}$ of around 6.5. This activity is constitutive and strictly limited to alcoholic fermentation. No vinylphenol can therefore be synthesized in a dry wine stored in the presence of yeast lees (Goodey \& Tubb, 1982; Gramatica et al., 1982).

The biosynthesis of ethylphenols by Brettanomyces/Dekkera has shown that a cinnamate decarboxylase transforms certain cinnamic acids into the corresponding vinylphenols, which are then reduced to ethylphenols by a vinylphenol reductase (Fig. 6b) (Chatonnet et al., 1992).

Yeast strain effect on volatile phenol production: Chatonnet $e t$ al. (1992) tested yeasts isolated from different fermented media (wines, beers pineaux, ciders, vinegars) in a model medium containing trans-p-coumaric acid substrate. The microorganims varied in their ability to decarboxylate $p$-coumaric acid into 4vinylphenol (Table 13). Only the yeasts belonging to the genus Brettanomyces and Dekkera could transform substantial amounts of $p$-coumaric acid into 4-ethylphenol.

Van Wyk \& Rogers (2000) showed that the phenolic and elastoplast off-odours present in some Kerner tabel wines is due to the production of $p$-vinylguaiacol by wine yeast strains during the alcoholic fermentation. They showed that the ability of $18 \mathrm{com}-$ 
TABLE 13

Synthesis of volatile phenols from $p$-coumaric acid by different yeasts (Chatonnet et al., 1992)

\begin{tabular}{|c|c|c|}
\hline \multirow{2}{*}{ Microorganisms } & \multicolumn{2}{|c|}{ Transformation of $p$-coumaric acid ${ }^{\mathrm{a}}$} \\
\hline & 4-Vinylphenol & 4-Ethylphenol \\
\hline Candida vini MUCL 27720 & - & - \\
\hline Candida freychussi MUCL 27714 & ++++ & - \\
\hline Hanseniaspora uvarum MUCL 27770 & + & - \\
\hline Metschnikovia pulcherina MUCL 277876 & - & - \\
\hline Pichia membranefaciens MUCL 27734 & - & - \\
\hline Hansenula anomala MUCL 27753 & +++ & - \\
\hline Saccharomyces cerevisiae (italicus) ICEB & +++ & - \\
\hline Saccharomyces cerevisiae (chevalieri) IEB & + & - \\
\hline Saccharomyces cerevisiae (uvarum) ICEB & ++ & - \\
\hline Saccharomyces cerevisiae (carlbergensis) ICB & - & - \\
\hline Saccharomyces cerevisiae (capensis) ICEB & + & - \\
\hline Saccharomyces cerevisiae (cerevisiae) IEB & + & - \\
\hline Saccharomyces cerevisiae (cerevisiae) ICB & ++++ & - \\
\hline Saccharomyces cerevisiae (cerevisiae) ICB & +++ & - \\
\hline Saccharomyces cerevisiae (cerevisiae) IEB & + & - \\
\hline Saccharomyces cerevisiae (bayanus) ICB & ++ & - \\
\hline Kluyveromyces thermotolerans MUCL 28822 & + & - \\
\hline Torulaspora delbruchi MUCL 27816 & - & - \\
\hline Pichia carsenis IEB & + & - \\
\hline Pichia canadensis MUCL 27722 & + & - \\
\hline Saccharomycopsis fibuligera MUCL 11443 & + & - \\
\hline Zigosaccharomyces bailii ICEB & + & - \\
\hline Brettanomyces intermedius CBS & + & +++ \\
\hline Dekkera intermedia MUCL 11989 & + & +++ \\
\hline Brettanomyces lambicus IÆB SA & + & +++ \\
\hline
\end{tabular}

${ }^{a}-$, Negative; +/-, very weak $\leq 1 \%$ of the substrate;,$+ 1-20 \% ;++, 20-40 \% ;+++, 40-60 \% ;++++,>60 \%$

mercial wine yeast strains to produce $p$-vinylguaiacol varied significantly $(0-890 \mu \mathrm{g} / \mathrm{L})$.

\section{Sulfur compounds}

These substances can make a significant contribution to the flavour of wine because of their reactivity and extremely low threshold values. In some circumstances, they are responsible for undesirable sulfurous off-flavours (Schutte, 1975; Peppard, 1988). Many sulfur compounds are extremely flavour active and have thresholds far below $0.002 \mathrm{ppb}$ (Soltoft, 1988); these values vary depending on the wine variety in which they are measured and the taster. Table 14 lists some of the main sulfur compounds found in wine.

The production of hydrogen sulfide $\left(\mathrm{H}_{2} \mathrm{~S}\right)$ has been studied in detail, since its aroma is frequently detected during fermentation because of low nitrogen musts. Only a few reports exist on the synthesis of other flavour-active S-compounds. $\mathrm{H}_{2} \mathrm{~S}$ has an unpleasant aroma with a low sensory threshold $(10-100 \mu \mathrm{g} / \mathrm{L})$; values above its threshold cause an off-flavour reminiscent of rotten eggs. In young wines the production of $20-30 \mu \mathrm{g} / \mathrm{L}$ of $\mathrm{H}_{2} \mathrm{~S}$ may have a positive contribution to "yeasty" flavour (Dittrich \& Staudenmayer, 1970). Recent studies show that high amounts of $\mathrm{H}_{2} \mathrm{~S}$ can also lead to the formation of other undesirable volatile sulfur compounds (Rauhut \& Kürbel, 1994a, b). In the past, one of the main sources of $\mathrm{H}_{2} \mathrm{~S}$ was the reduction of elemental sulfur by wine yeasts from residues originating with applications of dusting sulfur in the vineyard as fungicide (Schütz \& Kunkee, 1977). Chemical breakdown of S-containing pesticides (e.g. acephate) can also be the cause of odour-active Ssubstances like methyl mercaptane (Rauhut et al., 1986).

Analysis of 100 wines showed that wines with a sulfurous offflavour had increased concentrations of methyl mercaptane 
TABLE 14

Some volatile sulfur substances produced by yeast and their concentrations, threshold values and odours in wine (Shreier, 1979; Goniak \& Noble, 1987; Rauhut, 1993).

\begin{tabular}{lccl}
\hline Compound & $\begin{array}{c}\text { Conc. in wine } \\
(\mu \mathrm{g} / \mathrm{L})\end{array}$ & $\begin{array}{c}\text { Threshold } \\
\text { value }(\mu \mathrm{g} / \mathbf{L})\end{array}$ & \multicolumn{1}{c}{ Odour } \\
\hline Hydrogen sulfide & Trace- $>80$ & $50-80$ & Rotten eggs \\
Dimethyl sulfide & Trace-910 & $25-60$ & Asparagus, corn, molasses \\
Diethyl sulfide & Traces & 0.92 & Cooked vegetables, onion, garlic \\
Dimethyl disulfide & Traces-1.6 & 29 & Cooked cabbage, onion-like \\
Diethyl disulfide & Traces & 4.3 & Garlic, burnt rubber \\
Methyl mercaptan & Qualitive & $2-12^{*}$ & Rotten eggs, cabbage \\
Ethyl mercaptan & Qualitive & 1.1 & Onion, rubber \\
S-methyl thioacetate & $2-16$ & $300^{*}$ & Rotten vegetables \\
S-ethyl thioacetate & Traces-4 & $40^{*}$ & Cheesy, burnt \\
4-Mercapto-4-methylpentan-2-ol & Traces & $3 \times 10^{-6}$ & Box tree, cat urine, guava, conifer \\
\hline
\end{tabular}

*Beer

(MeSH), ethyl mercaptane (EtSH), dimethyl disulphide (DMDS), methyl ethyl disulfide (MeSSEt), diethyl disulfide (DEDS), thioacetic acid-S-methyl ester (MeSAc) and thioacetic acid-Sethyl ester (EtSAc), as well as other known and unknown S-compounds (Rauhut \& Kürbel, 1996).

Three flavour-active volatile thiols (4-mercapto-4-methylpentan-2-one, 4-mercapto-4-methylpentan-2-ol and 3-mercaptohexan-1-ol) involved in Vitis vinifera L. var. Sauvignon blanc wine aroma (box tree, broom, passion fruit, guava and "conifer") were recently identified (Darriet et al., 1995; Tominaga et al., 1998a). These compounds have very low threshold values and are produced by yeast during the alcoholic fermentation from grape precursors.

Tominaga et al. (1996) identified 3-mercaptohexyl acetate in Sauvignon wine. This mercapto ester, recently found in passionfruit, exhibits aroma reminiscent of box tree with grapefruit and passion fruit notes. Its perception threshold in water and model solution is around 2-4 ng/L. 3-Mercaptohexyl acetate may contribute to the typical varietal aroma of Sauvignon blanc wines (Tominaga et al., 1996).

Biosynthesis of sulfur compounds by yeast: Several biological and chemical factors affect production of $\mathrm{H}_{2} \mathrm{~S}$. As a product of the Sulfate Reduction Sequence (SRS), $\mathrm{H}_{2} \mathrm{~S}$ is an intermediate in the biosynthesis of all sulfur-containing compounds, including the amino acids, methionine and cysteine, and the methyl-group donor S-adenosylmethionine. Consequently its formation in wine is related to both sulfur and nitrogen metabolism by yeasts (Fig. 7). For detailed reviews see Rauhut (1993), and Henschke \& Jiranek (1993b). In a series of regulated steps in the SRS, sulfate is accumulated from the medium and then reduced to sulfide via two ATP activation steps. At this point, sulfide is combined enzymatically with the nitrogen-containing carbon precursors, $O$ acetyl serine and $O$-acetyl homoserine, to ultimately form cysteine and methionine. The SRS is activated to produce sulfide whenever there is a metabolic demand for cysteine and methionine, since only limited amounts are present in grape juice. When a general deficiency of nitrogen coincides with a demand for protein synthesis, an intracellular depletion of nitrogen will ultimately result. A concomitant deficiency of the nitrogenous precursors of sulfur-amino acid biosynthesis, and in turn methionine, cysteine and their regulatory derivatives, will derepress the SRS and $\mathrm{H}_{2} \mathrm{~S}$ will be produced (Vos \& Gray, 1979). Because sulfite freely diffuses into the cell, it essentially bypasses all regulatory steps normally controlling its production; therefore, a high and sustained rate of $\mathrm{H}_{2} \mathrm{~S}$ production is observed in response to a nitrogen deficiency when cells are grown in the presence of sulfite (Stratford \& Rose, 1986).

Increased $\mathrm{H}_{2} \mathrm{~S}$ production can occur during fermentation at higher temperatures, at higher $\mathrm{pH}$ values, in musts that have a higher content of solids, etc. (Rauhut, 1993). A deficiency in a readily available nitrogen supply in the must is an important cause of $\mathrm{H}_{2} \mathrm{~S}$ formation by yeasts. Rauhut \& Kürbel (1994a, b) showed that a high $\mathrm{H}_{2} \mathrm{~S}$ production caused by elemental sulfur residues was responsible for an increased concentration of other volatile S-compounds during and after fermentation by yeast metabolism. This leads to the formation of high amounts of thioacetic acid-S-methyl ester (MeSAc), thioacetic acid-S-ethyl ester (EtSAc) and other unknown S-substances. These thioacetic acid esters can slowly hydrolyze in wine to methyl and ethyl mercaptane, causing sulfur aroma defects, because in contrast to the thioacetic acid esters $(>40 \mathrm{mg} / \mathrm{L})$, the mercaptans have very low threshold values $(>5 \mu \mathrm{g} / \mathrm{L})$. Therefore, sulfur aroma defects can increase or reoccur during storage, since copper sulfate treatment removes only $\mathrm{H}_{2} \mathrm{~S}$ and mercaptans, while thioacetic acid esters still remain. The mercaptans can in the presence of oxygen be oxidised to disulfides, which are also odour-active compounds. Disulfides are likewise not removable by copper sulfate treatment (Rauhut et al., 1996).

Another source of $\mathrm{H}_{2} \mathrm{~S}$ is the reduction of elemental sulfur, originating from applications of dusting elemental sulfur in the vineyard as a fungicide, by wine yeasts (Schütz \& Kunkee, 1977). The chemical breakdown of S-containing insecticides can 


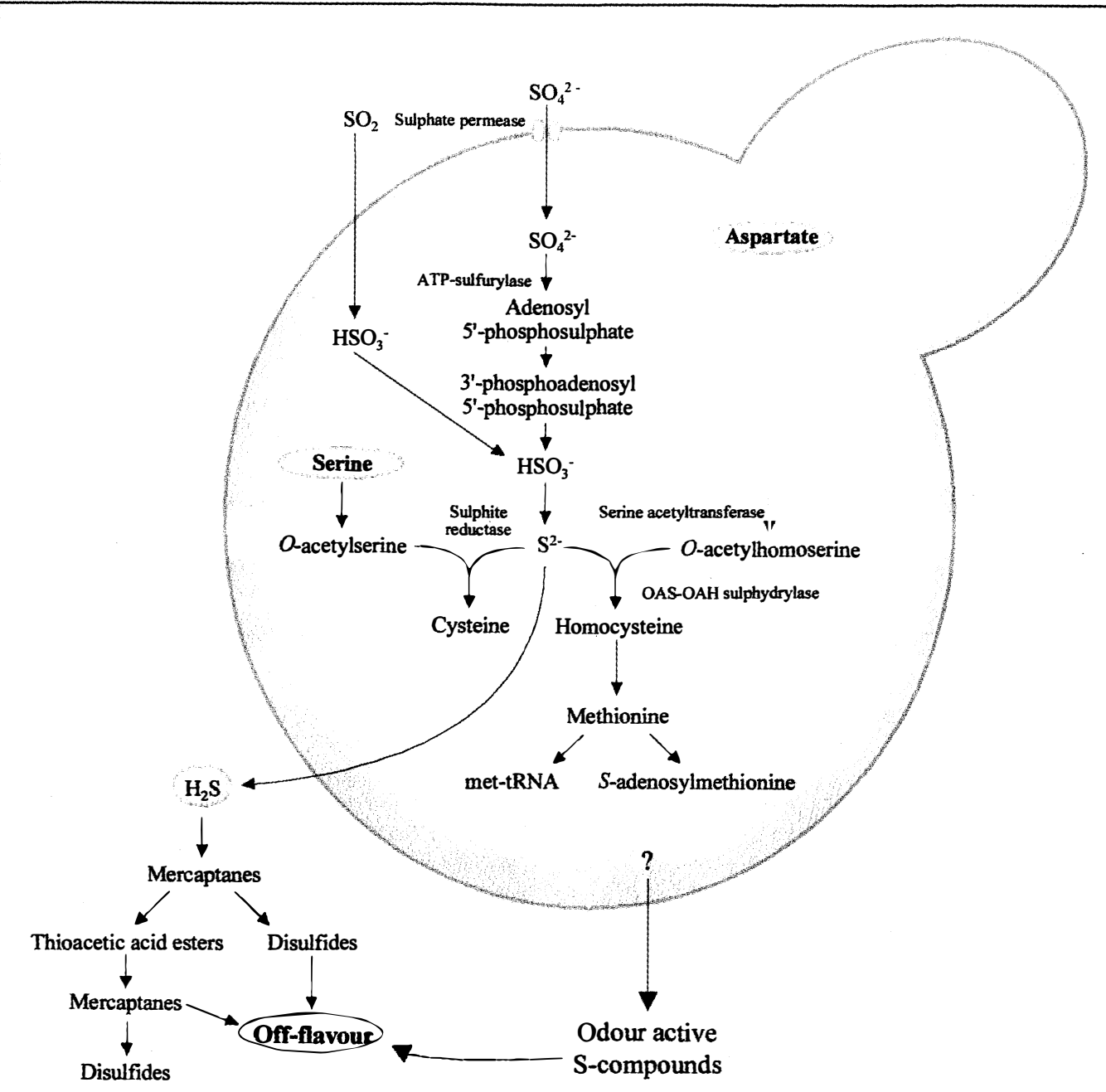

FIGURE 7

A schematic representation of the formation of odour-active S-compounds (Rauhut, 1993; Rauhut et al., 1996).

also be the cause of odour-active S-substances like methylmercaptane (Rauhut et al., 1986).

S-methylmethionine is the main precursor of DMS (Bamforth, 1980). It was also indicated that DMS might be synthesized by yeasts from cystine, cysteine or glutathione (Schreier et al., 1976; De Mora et al., 1986). De Mora et al. (1986) have shown that mercaptans are formed from methionine by yeast metabolism.

The volatile thiols 4-mercapto-4-methylpentan-2-one, 4-mercapto-4-methylpentan-2-ol and 3-mercaptohexan-1-ol, which are responsible for box tree, broom, passion fruit, guava and conifer aromas in Sauvignon blanc wines, were shown by Tominaga et $a l$. (1998b) to be formed by yeast during the alcoholic fermentation due to the degradation of the corresponding S-cysteine conjugates present in the grapes.

Yeast strain effect on sulfur aroma compound formation: The production of $\mathrm{H}_{2} \mathrm{~S}$ varies with the strain of $S$. cerevisiae, with some strains producing amounts exceeding $1 \mathrm{mg} / \mathrm{L}$ (Acree et al., 1972; Eschenbruch et al., 1978; Vos \& Gray, 1979). Rauhut et al. (1996) tested the ability of several commercial wine yeasts to produce volatile S-compounds by comparing the sulfur aromagrams from fermentation trials with the same must. Their results clearly showed that $S$. cerevisiae strains differ in their capacity to synthesize S-compounds (Table 15). Some strains were responsible for sulfur off odours in wines correlating to high concentrations of S-compounds. Some strains showed a slight increase in the formation of S-compounds producing wines with no offflavour, but masking the typical aroma of the variety.

Nearly all studies to date concern the biochemical activities of $S$. cerevisiae; virtually no attention has been given to the production of S-compounds by other species, some of which (e.g. Kloeckera, Hanseniaspora and Candida spp.) can make significant contributions to wine fermentations.

\section{EFFECT OF INDIGENOUS AND INOCULATED YEAST ON WINE AROMA}

As mentioned, several studies have shown that various starter cultures and indigenous yeasts produce wines with significant differences in chemical composition, with some of the compounds produced above and others below their sensory threshold 


\section{TABLE 15}

Influence of the yeasts strain on the concentration of $\mathrm{H}_{2} \mathrm{~S}$, methionol and the total amount of volatile S-substances (Rauhut et al., 1996). in ester production by yeast strains (Delteil \& Jarry, 1992).

\begin{tabular}{lcccccc}
\hline $\begin{array}{l}\text { S. cerevisiae } \\
\text { strain no. }\end{array}$ & $\begin{array}{c}\text { Intensity of } \mathbf{H}_{2} \mathbf{S} \\
\text { formation during } \\
\text { fermentation }\end{array}$ & $\begin{array}{c}\mathbf{H}_{2} \mathbf{S} \mu \mathrm{g} / \mathbf{L} \text { at the } \\
\text { end of } \\
\text { fermentation }\end{array}$ & $\begin{array}{c}\text { Methionol } \\
\text { AS/AIS* }\end{array}$ & $\begin{array}{c}\text { Sum of S- } \\
\text { substances }\end{array}$ & $\begin{array}{c}\text { Residual } \\
\text { sugar } \mathbf{~} / \mathbf{L}\end{array}$ & $\begin{array}{c}\text { Alcohol } \\
\mathbf{g} / \mathbf{L}\end{array}$ \\
\hline 1 & 1 & n.n. & 1.3 & 5.3 & 12.5 & 78.9 \\
2 & 3 & 17.0 & 5.4 & 18.0 & 2.2 & 82.1 \\
3 & 3 & 14.0 & 6.7 & 16.6 & 2.3 & 82.9 \\
4 & 2 & 5.0 & 7.1 & 22.2 & 2.5 & 82.4 \\
5 & 1 & 4.0 & 3.6 & 10.3 & 27.5 & 71.9 \\
6 & 1 & 14.0 & 4.4 & 12.6 & 2.4 & 82.9 \\
7 & 1 & 4.0 & 5.0 & 13.9 & 6.4 & 81.0 \\
8 & 3 & 12.0 & 7.0 & 18.8 & 1.9 & 84.1 \\
9 & 4 & 8.0 & 11.0 & 31.3 & 4.9 & 81.9 \\
\hline
\end{tabular}

Intensity of $\mathrm{H}_{2} \mathrm{~S}$-formation: weak: 1, middle: 2 , strong: 3 , very strong: 4

${ }^{2}$ Sum of relative peak area of the $S$-substances

*AS/AIS: area of the S-substance/area of the internal standard (relative peak area)

values. Although this should result in sensory differences in the resultant wines, little was done in these studies to measure them. Recently two studies were conducted that specifically investigated the effect of indigenous and inoculated yeasts on the sensory character of the resultant wines (Egli et al., 1998; Henick-Kling et al., 1998).

Henick-Kling et al. (1998) used Riesling musts, with and without sulfur dioxide added, which were fermented with and without the addition of yeast. There were no significant differences in growth of non-Saccharomyces yeasts in uninoculated musts with less than $50 \mathrm{mg} / \mathrm{L} \mathrm{SO}_{2}$ added. The starter culture was completely dominant over indigenous $S$. cerevisiae and strongly inhibitory to non-Saccharomyces yeasts. Sensory scores for overall quality indicated that the uninoculated wines were as acceptable as those fermented with a commercial starter culture. Uninoculated fermentations had higher sensory scores $(\mathrm{P}>0.95)$ (typical fruity descriptors) for spicy, apple, melon, pear and $\mathrm{H}_{2} \mathrm{~S}$, while inoculated wines had higher scores $(\mathrm{P}>0.95)$ for paper, oxidized and sweaty, generally considered to be unfavourable. They concluded that the increased fruitiness in the uninoculated wines was due to the contributions by the non-Saccharomyces yeasts and by indigenous Saccharomyces yeasts. The K-1M starter culture used in the experiment did not promote fruity flavours. Sulfite treatment produced an assortment of significant sensory differences in the finished uninoculated wines, but in inoculated wines the additions of $\mathrm{SO}_{2}$ to the must had no significant effect on indigenous yeast populations or on flavour.

In another study Egli et al. (1998) studied the dynamics of indigenous and inoculated yeast populations (vigorous and slowly fermenting yeast) and their effect on the sensory character of Riesling and Chardonnay wines. Both added starter cultures (strains EC1118 and Assmannshausen) clearly dominated the Saccharomyces population from the middle of fermentation until the end. The starter cultures differed in their repression of indigenous non-Saccharomyces yeast. Strain EC1118 limited the growth of non-Saccharomyces yeasts more strongly than strain Assmanshausen, since it is a more vigorous starter culture. The growth of non-Saccharomyces yeasts was further repressed by the addition of sulfite. At the end of the alcoholic fermentation more than one Saccharomyces strain was present in each fermentation, with the largest variety in the non-inoculated and the smallest in the EC1118-inoculated fermentation.

Riesling and Chardonnay wines from the three different fermentation types were compared by a trained taste panel. Interestingly, a very similar set of descriptors was chosen in describing the wines produced from the same grape variety (Table 16). Comparison of the scores for the wines revealed significant differences for some of the descriptors used for both the Riesling and Chardonnay wines (Table 16). Furthermore, the flavours that varied depending on the fermentation type did not overlap at all for the Riesling and Chardonnay wines. The wines from non-inoculated fermentations had the majority of high scores for these descriptors, while Riesling wines fermented with strain EC1118 had the lowest scores for these descriptors (Fig. 8). Assmannshausen-inoculated wines were generally between these extremes, but showed high scores for overall fruitiness and acetic, and lowest scores for diacetyl and paper. For both the Riesling and Chardonnay wines, the highest scores for most flavour attributes were given to wines from non-inoculated fermentations. The uninoculated Chardonnay wines were characterized by floral and pear aromas and by strong vegetative, reduced and sweaty aromas. Wines fermented with Assmannshausen tended to have more fruity flavours (floral and pear), and EC1118-inoculated wines were less fruity and had stronger oxidized, astringent and some sweaty and herbaceous flavours. Importantly, these yeastrelated differences did not overwhelm the varietal character.

Statistical analysis revealed that the descriptors which were significantly different among Riesling wines were not the same as those which described significant differences in Chardonnay wines (Table 16). This suggests that the different yeasts affected 
TABLE 16

Aroma descriptors selected through Free-Choice Profiling, for Riesling and Chardonnay wines, affected by yeast (Egli et al., 1998).

\begin{tabular}{ll}
\hline Riesling & Chardonnay \\
\hline Acetic & Apple \\
Apple & Astringent/phenolic \\
Astringent/phenolic & \\
Body & Caramelized \\
& Citrus \\
Citrus & \\
Diacetyl/caramelized & Earthy \\
Earthy & \\
Flinty & Floral \\
Floral & \\
Overall fruitiness & Herbaceous/vegetative \\
& Reduced sulphur/H $\mathbf{S}$ \\
$\mathrm{H}_{2} \mathrm{~S}$ & Melon \\
Melon & Mineral/flinty \\
& Oxidized \\
Oxidized & Paper/cardboard \\
Paper/cardboard & Pear \\
Pear & \\
Pineapple/tropical & SO ${ }_{2}$ \\
SO & Spicy \\
Spicy & Sweaty \\
Sweaty & Yeasty \\
Yeasty & Descriptors which had significant differences between inoculation treatments (spontaneous, vigorous yeast \\
starter EC1118 and slow fermenting starter Assmannshausen) $(\mathbf{P} \geq 0.05)$ are in bold. \\
\end{tabular}

the flavour compounds variety-specifically. Nevertheless, yeast strain characteristics were also observed (Fig. 8). Assmannshausen-inoculated wines tended to be strongly fruity and spicy in the Riesling, and floral and pear-like in the Chardonnay. Strain EC1118 produced the least fruity wines in this comparison, tending toward aldehyde/phenolic, paper, oxidized and astringent flavours. In non-inoculated wines, most flavour attributes, positive and negative, tended to be highest.

Both Henick-Kling et al. (1998) and Egli et al. (1998) clearly showed that different vinification parameters such as grape must, sulfite addition, fermentation temperature, starter cultures, etc. that affect the fermentation microflora will have an impact on the sensory characteristics of the resulting wine. The effect of single, co- and sequential Candida stellata and S. cerevisiae cultures on the aroma of Chardonnay wines has also been illustrated by Soden et al. (2000).

\section{GENETIC IMPROVEMENT OF WINE YEASTS}

The knowledge of the physiology of genetic reference strains of $S$. cerevisiae becoming available is a great help in directing the modification of industrial yeasts toward practical goals, even though the industrial strains and species are less characterized and their genetic make-up more complex (Hansen \& KiellandBrandt, 1996). Though some work has been done on the genetic make-up of other strains, most detailed studies on industrial strains have been made on lager brewing yeast. Examples include brewers' yeasts producing reduced amounts of diacetyl by overexpression of the ILV5 gene (Gjermansen et al., 1988; Goossens et al., 1993), or increased amounts of phenethyl alcohol due to a mutated ARO4 gene on a centromere plasmid (Fukuda et al., 1992).

Wine yeasts have been engineered to degrade malic acid (Ansanay et al., 1996) or to produce lactic acid (Dequin et al., 1999). It has also also been shown that in laboratory $S$. cerevisiae strains, a specific mutation in the ERG20 gene resulted in geraniol overproduction (Chambon et al., 1990).

In a recent study, Lilly et al. (2000) manipulated the expression levels of the ATF1 gene for its effect on the production of esters, important for the characteristic fruity odours of wine, brandy and 
A

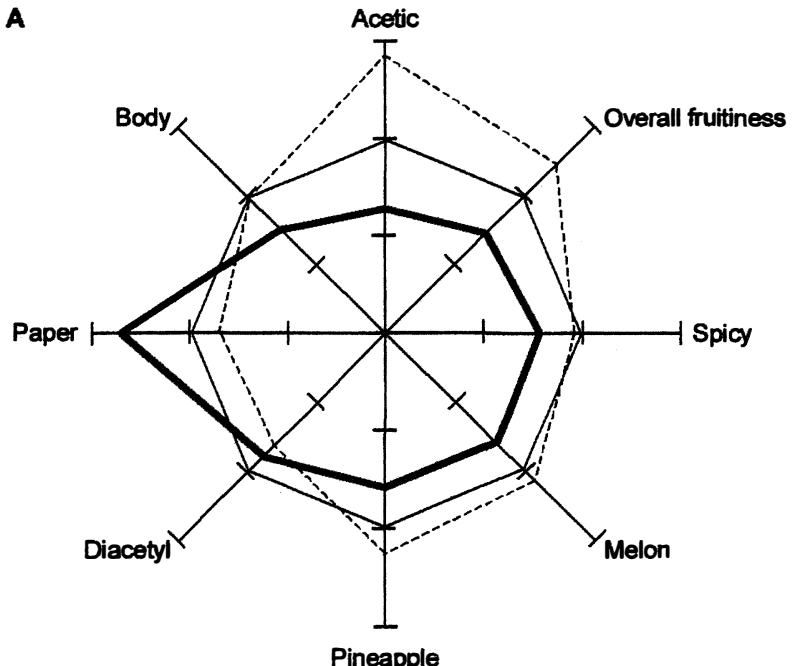

B

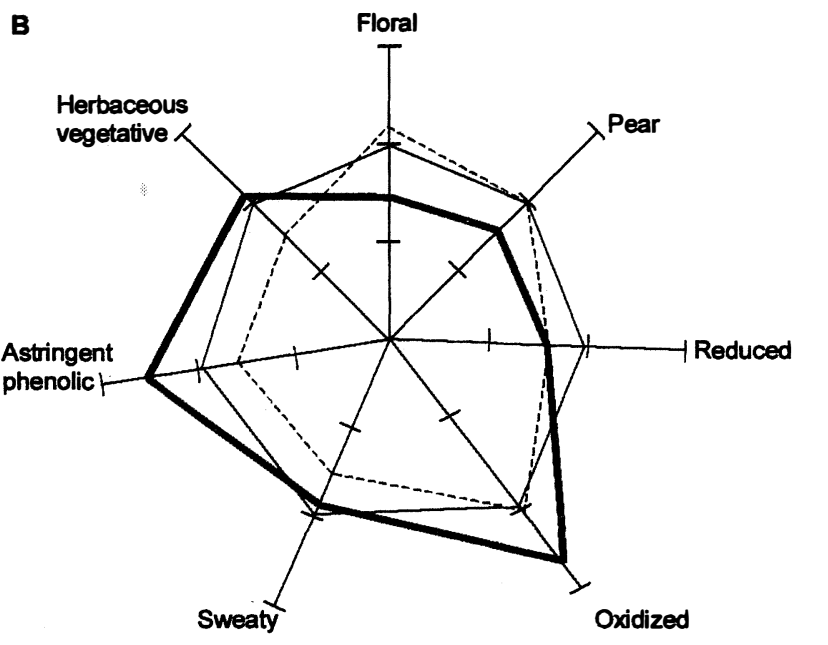

\section{FIGURE 8}

Sensory differences in Riesling (a) and Chardonnay (b) wines based on the fermentation type. Comparisons were made by a panel of 11 experienced tasters and data are described using polar graphs following statistical evaluation, (-), strain EC1118; (--), strain Assmannshausen; (-); non-inoculated (Egli et al., 1998).

other alcoholic beverages. The $A T F 1$-encoded alcohol acetyl transferase activity is the best studied acetyl transferase activity in $S$. cerevisiae. The ATF 1 gene, located on chromosome XV, was cloned from a widely used commercial wine yeast strain of $S$. cerevisiae, VIN13, placed under the control of the constitutive yeast phosphoglycerate kinase gene $(P G K 1)$ promoter and terminator, and integrated into the chromosomes of three commercial wine yeast strains. The sensorial evaluation of Chenin blanc wines and distillates from Colombar base wines, fermented with these manipulated wine yeasts, showed that overexpression of a single gene such as $A T F 1$ could alter ester production significantly, thereby adjusting the aroma profiles of wines and distillates considerably. The significant increases in the levels of ethyl acetate, isoamyl acetate and 2-phenylethyl acetate had pronounced effects on the solvent/chemical and the herbaceous and heads-associated aromas of the final distillate, and the solvent/ chemical and fruity or flowery characters of the Chenin blanc wines. This study established the concept that the overexpression of acetyltransferase genes such as $A T F l$ could profoundly affect the flavour profiles of wines and distillates deficient in aroma, thereby paving the way for the production of products maintaining a fruitier character for longer periods after bottling.

Considerable progress has been made in developing technology to construct new wine yeast strains over the past few years, although research in wine science has been slow to exploit the vast potential benefit of recombinant DNA technology to the wine consumer and industry alike. A comprehensive review has recently been published by Pretorius (2000).

\section{CONCLUDING REMARKS}

Starter cultures have been developed to ferment rapidly and consistently, producing wines with predictable and desirable characteristics. Nevertheless, indigenous non-Saccharomyces yeasts may have a significant and favourable effect on flavour development, and they merit consideration as useful tools in managing wine styles. The synergistic interactions among different yeast strains and their effect on wine sensory properties remain to be fully investigated: different $S$. cerevisiae starter cultures might be selected to enhance fruity flavours in wine; yeast combinations of different $S$. cerevisiae strains, and possibly $S$. cerevisiae with selected non-Saccharomyces strains, might be used to enhance profiles to produce flavour-unique wines. Since judicious use of sulfite can be used to limit the growth of wild yeasts, mixed or sequential inoculations may ultimately be designed to consistently produce wines with the desired flavours.

Future research might also identify more examples, as in the case of 4-mercapto-4-methylpentan-2-one in Sauvignon blanc aroma, where yeasts contribute to varietal aroma. Recently, King $\&$ Dickinson (2000) have shown that $S$. cerevisiae can reduce the monoterpenoid geraniol into $R-(+)$-citronellol, and also isomerizes geraniol into linalool. The yeasts $T$. delbreuckii and $K$. lactis were also shown to convert a variety of monoterpenoids. Although not yet tested in must and wines, such activities should have an effect on wine aroma.

Only when we have a much better understanding of yeast biodiversity, biogeography, ecology and the interaction within yeast communities and their metabolism will we be able to use them optimally in single, mixed or sequential starter cultures and to improve them with gene technology. To achieve this, a comprehensive, long-term biological survey programme has been launched by the Wine and Fermentation Technology Division at the ARC Infruitec-Nietvoorbij, and the Institute for Wine Biotechnology at the University of Stellenbosch (Pretorius et al., 1999; Khan et al., 2000; Van der Westhuizen et al., 2000a, b). This kind of biological survey complements the current international effort to assign a biological function to the products of each of the 6000 genes indentified by computer analysis of the nucleotide sequence of the 16 chromosomes of a laboratory strain of $S$. cerevisiae (Oliver, 1996; Mewes et al., 1997). Some of the new genes will certainly be appropriate targets for modification of metabolic pathways in $S$. cerevisiae, and, due to the close relationship, industrial Saccharomyces yeast. Furthermore, a research programme to understand the role of esters and other volatile 
compounds and to clone genes from $S$. cerevisiae involved in wine aroma has also been initiated at the Institute for Wine Biotechnology (Lilly et al., 2000). With the important contribution of non-Saccharomyces yeasts now fully realised, future research programmes should focus on this group, containing a wide variety of yeasts that have been shown to produce a diverse array of extracellular enzymes compared to $S$. cerevisiae (Charoenchai et al., 1997; Strauss et al., 2000).

\section{LITERATURE CITED}

ACREE, T.E., SONOFF, E.P. \& SPLITTSTOESSER, D.F., 1972. Effect of yeast strain and type of sulfur compounds on hydrogen sulfide production. Am. J. Enol. Vitic. 23, 6-9.

ALEXANDRE, H. \& CHARPENTIER, C., 1998. Biochemical aspects of stuck and sluggish fermentation in grape must. J. Ind. Microbiol. Biotechnol. 20, 20-27. AMERINE, A.M., BERG, H.V., KUNKEE, R.E., OUGH, C.S., SINGLETON, V.L. \& WEBB, A.D., 1980. The technology of winemaking. ( $4^{\text {th }}$ ed.). Westport, CT: AVI Technical Books Inc.

AMERINE, A.M. \& CRUESS, W.V., 1960 . The technology of winemaking. $\left(2^{\text {nd }}\right.$ ed.). Westport, CT: AVI Publishing Co.

AMERINE, M.A. \& OUGH, C.S., 1980. Alcohols. In: Methods for Wine and Must Analysis. John Wiley and Sons, Inc., New York. pp. 74-127.

ANDREASEN, A.A. \& STIER, T.J.B., 1954. Anaerobic nutrition of Saccharomyces cerevisiae I. Ergosterol requirement for growth in a defined medium. J. Cell Comp. Physiol. 41, 23-26.

ANSANAY, V., DEQUIN, S., CAMARASA, C., SCHAEFFER, V., GRIVET, J.P., BLONDIN, B., SALMON, J.-M. \& BARRE, P., 1996. Malolactic fermentation by engineered Saccharomyces cerevisiae as compared with engineered Schizosaccharomyces pombe. Yeast 12, 215-225.

ANTONELLI, A., CASTELLARI, L., ZAMBONELLI, C. \& CARNACINI, A., 1999. Yeast influence on volatile composition of wines. J. Agric. Food Chem. 47, 1139-1144.

ÄYRÄPÄÄ, T., 1961. Occurrence of phenethyl alcohol in beer. J. Inst. Brew. 67, 262-266.

ÄYRÄPÄÄ, T., 1962. Estimation of phenethyl alcohol in fermentation products. J. Inst. Brew. 68, 504-508.

ÄYRÄPÄÄ, T., 1963. Formation of phenethyl alcohol during alcoholic fermentation, compared with the formation of aliphatic fusel alcohols. In: Proceedings of the European Convention, Brussels. pp. 271-283.

ÄYRÄPÄ̈̈, T., 1965. The formation of phenethyl alcohol from ${ }^{14} \mathrm{C}$-labelled phenylalanine. J. Inst. Brew. 71, 341-347.

ÄYRÄPÄÄ, T. 1967. Formation of higher alcohols from ${ }^{14} \mathrm{C}$-labelled valine and leucine. J. Inst. Brew. 73, 17-30.

ÄYRÄPÄÄ, T. 1968. Formation of higher alcohols by various yeasts. J. Inst. Brew. 74, 169-179.

ÄYRÄPÄÄ, T. 1971. Biosynthetic formation of higher alcohols by yeast. Dependence on the nitrogenous nutrient level of the medium. J. Inst. Brew. 77, 266-276.

BAMFORTH, C.W., 1980. Dimethyl sulfoxide reductase of Saccharomyces spp. FEMS Microbiol. Lett. 7, 55-59.

BARDI, L., CRIVELLI, C. \& MARZONA, M., 1998. Esterase activity and release of ethyl esters of medium-chain fatty acids by Saccharomyces cerevisiae during anaerobic growth. Can. J. Microbiol. 44, 1171-1176.

BARNETT, J.A., PAYNE, R.W. \& YARROW, D., 1979. A guide to identifying and classifying yeasts. Cambridge University Press, London.

BAUMES, R., CORDONNIER, R., NITZ, S. \& DRAWERT, F., 1986. Identification and determination of volatile constituents in wines from different vine cultivars. J. Sci. Food Agric. 37, 927-943

BENNETZEN, J. \& HALL, B. D., 1982. The primary structure of $S$. cerevisiae gene for alcohol dehydrogenase. J. Biol. Chem. 257, 3018-3025.

BERG, H., FILIPELLO, F., HINREINER, E. \& WEBB, A., 1955. Evaluation of thresholds and minimum difference concentrations for various constituents of wines: I. Water solutions for pure substances. Food Technol. 9, 23-26.

BERRY, D.R., 1995. Alcoholic beverage fermentations. In: LEA, A.G.H. \& PIGGOTT, J.R. (eds). Fermented beverage production. Blackie Academic \& Professional, Glasglow. pp. 32-44.

BOULTON, R.B., SINGLETON, V.L., BISSON, L.F. \& KUNKEE, R.E., 1995. Principles and practices of winemaking. Chapman Hall, New York.
CALDERBANK, J. \& HAMMOND, J.R.M., 1994. Influence of higher alcohol availability on ester formation by yeast. J. Am. Soc. Brew. Chem. 52, 84-90.

CASSALONE, E., COLlELA, C. M., DALY, S. \& GALLORI, E., 1992. Mechanism of resistance to sulphite in S. cerevisiae. Curr. Genet. 22, 435-440.

CASTELLA, P.M., MESIAS, J.L. \& MAYNAR, J.L., 1985. Évolution de la teneur en lipides totaux, neutres et polaires dans les raisins Macabeo (Vitis vinifera) au cours de leur cycle végétatif. Sciences des Aliments 5, 587-597.

CAVIN, J.F., ANDIOC, V., ETIEVANT, P.X. \& DIVIES, C., 1993. Ability of wine lactic acid bacteria to metabolize phenol carboxylic acids. Am. J. Enol. Vitic. 31, 76-80.

CHAMBON, C., LAdEVEZE, V., OUlMOUdEN, A., SERVOUSE, M. \& KARST, F., 1990. Isolation and properties of yeast mutants affected in farnesyl diphosphate synthetase. Curr. Genet. 18, 41-46.

CHAROENCHAI, C., FLEET, G.H., HENSCHKE, P.A. \& TODD, B.E.N., 1997. Screening of non-Saccharomyces wine yeasts for the presence of extracellular hydrolytic enzymes. Austr. J. Grape Wine Res. 3, 2-8.

CHATONNET, P., BIODRON, J.N. \& PONS, M., 1990. Elevage des vins rouges en fûts de chéne: evolution de certains composés volatils et de leur impact aromatique. Sci. Aliment. 10, 565-587.

CHATONNET, P., DUBOURDIEU, D. \& BOIDRON, J., 1995. The influence of Brettanomyces/Dekkera sp. yeasts and lactic acid bacteria on the ethylphenol content of red wines. Am. J. Enol. Vitic. 46, 463-467.

CHATONNET, P., DUBORDIEU, D., BOIDRON, J.N. \& LAVIGNE, V., 1993. The synthesis of volatile phenols by S. cerevisiae in wine. J. Sci. Food Agric. 62, 191-202.

CHATONNET, P., DUBOURDIEU, D., BOIDRON, J. \& PONS, M., 1992. The origin of ethylphenols in wines. J. Sci. Food Agric. 60, 178-184.

CHATONNET, P., VIALA, C. \& DUBOURDIEU, D., 1997. Influence of polyphenolic components of red wines on the microbial synthesis of volatile phenols. Am. J. Enol. Vitic. 48, 443-448.

CORISON, C.A., OUGH, C.S., BERG, H.W. \& NELSON, K.E., 1979. Must acetic acid and ethyl acetate as mold rot indicators in grapes. Am. J. Enol. Vitic. 30, $130-134$

DARRIET, P., TOMINAGA, T., LAVIGNE, V., BOIDRON, J.N. \& DUBOURDIEU, D., 1995. Identification of a powerful aromatic component of Vitis vinifera L. var. Sauvignon wines: 4-mercapto-4-methylpentan-2-one. Flavour Fragrance J. 10, 385-392.

DAUDT, C.E. \& OUGH, C.S., 1973. Variations in some volatile acetate esters formed during grape juice fermentation. Effects of fermentation temperature, $\mathrm{SO}_{2}$, yeast strain, and grape variety. Am. J. Enol. Vitic. 24, 130-135.

DAVIS, C.R., WIBOWO, D., ESCHENBRUCH, R.E., LEE, T.H. \& FLEET, G.H., 1985. Practical implications of malolactic fermentation: a review. Am. J. Enol. Vitic. 36, 290-301.

DELFINI, C. \& CERVETTI, F., 1987. Enquete experimentale sur la formation de grandes quantités d'acide acetique au cours de la fermentation alcoolique. Rev. des Oenologues 9, 20-27.

DELFINI, C. \& CERVETTI, F., 1991. Metabolic and technological factors affecting acetic acid production by yeasts during alcoholic fermentation. Vitic. Enol. Sci. 46, 142-150.

DELFINI, C., CONTERNO, L., GIACOSA, D., COCITO, C., RAVAGLIA, S. \& BARDI, L., 1992. Influence of clarification and suspended solid contact on the oxygen demand and long chain fatty acid contents of free-run, macerated and pressed grape musts in relation to acetic acid production. Vitic. Enol. Sci. 47, 6975 .

DELFINI, C. \& COSTA, A., 1993. Effects of grape must lees and insoluble materials on the alcoholic fermentation rate and the production of acetic acid, pyruvic acid and acetaldehyde. Am. J. Enol. Vitic. 44, 102-107.

DELFINI, C., GAIA, P., BARDI, L., MARISCALCO, G. \& CONTEIRO, M., 1991. Production of benzaldehyde, benzyl alcohol and benzoic acid by yeasts and Botrytis cinerea isolated from grape musts and wines. Vitis 30, 253-263.

DELTEIL, D. \& JARRY, J.M., 1992. Characteristic effects of two commercial yeast strains on Chardonnay wine volatiles and polysaccharide composition. Austr. N.Z. Wine Ind. J. 7, 29-33.

DE MORA, S.J., ESCHENBRUCH, R., KNOWLESM, S.J. \& SPEDDING, D.J., 1986. The formation of dimethyl sulfide during fermentation using a wine yeast. Food Microbiol. 3, 27-32.

DENIS, C.L., FERGUSON, J. \& YOUNG, E.T., 1983. mRNA levels for the fermentative alcohol dehydrogenase of $S$. cerevisiae decrease upon growth on a nonfermentable carbon source. J. Biol. Chem. 258, 1165-1171. 
DEQUIN, S., BAPTISTA, E. \& BARRE, P., 1999. Acidification of grape musts by Saccharomyces cerevisiae expressing the Lactobacillus casei $\mathrm{L}(+)-\mathrm{LDH}$. Bio/Technol. 12, 173-177.

DE WET, P., 1978. Odour thresholds and their application to wine flavour studies. Proc. S.A. Oenol. and Vitic. 3-4 Oct. pp. 72-77.

DI STEFANO, R., CIOLFI, G. \& DELFINI, C., 1981. Composti volatili prodotti dai lieviti. Riv. Vitic. Enol. 34, 342-355.

DITTRICH, H.H. \& STAUDENMAYER, T., 1970. Uber die Zusammenhänge zwischen der Sulfit-Bildung und der Schwefelwasserstoff-Bildung be Saccharomyces cerevisiae. Zentralblatt für Bakteriologie, Parasitenkunde, Infektionshrankhbeiten und Hygiene, II Abt. Bd. 124, 113-118.

DUBOIS, P., 1983. Volatile phenols in wine. In: PIGGOT, J.R. (ed). Flavour of distilled beverages, origin and development, Ellis Horwood. Chichester. pp. 110119.

DUBOIS, P., 1994a. Les arômes des vins et leurs dé fauts. Rev. Fr. Enol. 145, 2740.

DUBOIS, P., 1994b. Les arômes des vins et leurs dé fauts. Rev. Fr. Enol. 146, 3950.

DUFOUR, J.P. \& MALCORPS, P., 1994. Ester synthesis during fermentation: enzyme characterization and modulation mechanism. Proc. Congr. Eur. Brew. Conv. pp. 137-151.

EBELER, S.E. \& SPALDING, R.S., 1999. Characterization and measurement of aldehydes in wine. In: WATERHOUSE, A.L. \& EBELER, S.E. (eds). Chemistry of wine flavor ACS symposium series. Oxford University Press. pp. 166-179.

EDWARDS, T.L., SINGLETON, V.L. \& BOULTON, R., 1985. Formation of ethyl esters of tartaric acid during wine aging: Chemical and sensory effects. Am. J. Enol. Vitic. 36, 118-124.

EGLI, C.M., EDINGER, W.D., MITRAKUL, C.M. \& HENICK-KLING, T., 1998. Dynamics of indigenous and inoculated yeast populations and their effect on the sensory character of Riesling and Chardonnay wines. J. Appl,. Microbiol. 85, 779-789.

EGLINTON, J.M. \& HENSCHKE, P.A., 1999. The occurrence of volatile acidity in Australian wines. Australian Grapegrower \& Winemaker. pp. 7-12.

ENGAN, S., 1974. Esters in beer. Brew. Dig. 49, 40-48.

ESCHENBRUCH, R., BONISH, P. \& FISHER, B.M., 1978. The production of $\mathrm{H}_{2} \mathrm{~S}$ by pure culture wine yeasts. Vitis 17, 67-74.

ETIEVANT, P.X., 1981. Volatile phenol determination in wine. J. Agric. Food Chem. 29, 65-67.

ETIEVANT, P.X., 1991. Wine. In: MAARSE (ed). Volatile compounds in foods and beverages. Marcel Dekker Inc., New York. pp. 483-587.

FALQUÉ, E. \& FERNÁNDEZ, E., 1996. Effects of different skin contact times on Treixadura wine composition. Am. J. Enol. Vitic. 47, 309-312.

FERREIRA, V., FERNÁDEZ, P., PEÑA, C., ESCUDERO, A. \& CACHO, J.F., 1995. Investigation on the role played by fermentation esters in the aroma of young spanish wines by multivariate analysis. J. Sci. Food Agric. 67, 381-392.

FLEET, G.H. \& HEARD, G.M., 1993. Yeasts: growth during fermentation. In: FLEET, G.H. (ed). Wine microbiology and biotechnology. Harwood Academic Publishers, Chur, Switzerland. pp. 27-54.

FLEET, G.H., LAFON-LAFOURCADE, S. \& RIBEREAU-GAYON, P., 1984. Evolution of yeasts and lactic acid bacteria during fermentation and storage of Bordeaux wines. Appl. Environ. Microbiol. 48, 1034-1038.

FUJII, T., NAGASAWA, N., IWAMATSU, A., BOGAKI, T., TAMAI, Y. \& HAMACHI, M., 1994. Molecular cloning, sequence analysis, and expression of the yeast alcohol acetyltransferase gene. Appl. Environ. Microbiol. 6, 2786-2792. FUKUDA, K., WATANABE, M., ASANO, K., OUCHI, K. \& TAKASAWA, S., 1992. Molecular breeding of a saké yeast with a mutated ARO4 gene which causes both resistance to $o$-fluoro-DL-phenylalanine and increased production of bphenethyl alcohol. J. Ferm. Bioeng. 73, 366-369.

GAFNER, J., HOFFMAN, P., PULVER, D. \& SCHÜTZ, M., 1993. Neue Erkenntnisse zur Rolle von Hefen in der Weinbereitung. In 10 $10^{\text {th }}$ International Oenological Symposium, $3^{\text {rd }} 5^{\text {th }}$ May 1993, Montreux, Switzerland, International Association for Winery Technology and Management.

GALLENDER, J.F. \& PENG, A.C., 1980. Lipid and fatty acid compositions of different grape types. Am. J. Enol. Vitic. 31, 24-27.

GARCÍA, A.I., GARCÍA, L.A. \& DÍAZ, D.M., 1994. Prediction of ester production in industrial beer fermentation. Enzyme Microb. Technol. 16, 66-71.

GIL, J.V., MATEO, J.J., JIMÉNEZ, M., PASTOR, A. \& HUERTA, T., 1996. Aroma compounds in wine as influenced by apiculate yeasts. J. Food Sci. 61, $1247-1249$.
GIUDICI, P., ROMANO, P. \& ZAMBONELLI, C., 1990. A biometric study of higher alcohol production in Saccharomyces cerevisiae. Can. J. Microbiol. 36, 6164.

GIUDICI, P., ZAMBONELLI, C. \& KUNKEE, R.E., 1993. Increased production of $n$-propanol in wine by yeast strains having an impaired ability to form hydrogen sulphide. Am. J. Enol. Vitic. 44, 123-127.

GJERMANSEN, C., NILSSON-TILLGREN, T., PETERSEN, J.G.L., KRIELLAND-BRANDT, M.C., SIGSAARD, P. \& HOLMBERG, S., 1988. Towards diacetyl-less brewers' yeast. Influence of ilv2 and ilv5 mutations. J. Basic Microbiol. 28, 175-183.

GÔMEZ, E., LAENCINA, J. \& MARTINEZ, A., 1994. Vinification effects on changes in volatile compounds of wine. J. Food Sci. 59, 406-409.

GONIAK, O.J. \& NOBLE, A.C., 1987. Sensory study of selected volatile sulfur compounds in white wine. Am. J. Enol. Vitic. 38, 223-227.

GOODY, A. R. \& TUBB, R. S., 1982. Genetic and biochemical analysis of the ability of S. cerevisiae to decarboxylate cinnamic acids. J. Gen. Microbiol. 128, 2615-2620.

GOOSSENS, E., DEBOURG, A., VILLANUEBA, K.D. \& MASSCHELEIN, C.A., 1993. Decreased diacetyl production in lager brewing yeast by integration of the ILV5 gene. Proc. $24^{\text {th }}$ Congr. Eur. Brew. Conv., Oslo. pp. 251-258.

GRAMATICA, P., RANZI, B. M. \& MANNITO, P., 1982. Decarboxylation of cinnamic acids by $S$. cerevisiae. Biorg. Chem. 10, 21-24.

GUYMON, J.F., 1972. Higher alcohols in beverage brandy. Feasibility of control levels. Wines \& Vines 53, 37-39.

GUYMON, J.F., INGRAHAM, J.L. \& CROWELL, E.A., 1961. The formation of $n$-propyl alcohol by Saccharomyces cerevisiae. Arch. Biochem. Biophys. 95, $163-$ 168.

HANNEMANN, W., 1985. Ausscheiding von Essigsäure durch Gärende Hefen und die Reinigung und Charakterisierung einer NADP ${ }^{+}$-Spezifischen Aldehyddehydrogenase aus Saccharomyces cerevisiae. PhD Dissertation, Mainz.

HANSEN, J. \& KIELLAND-BRANDT, M.C., 1996. Modification of biochemical pathways in industrial yeasts. J. Biotechnol. 49, 1-12.

HENICK-KLING, T., 1993. Malolactic fermentation. In: FLEET, G.H. (ed). Wine microbiology and biotechnology. Harwood Academic Publishers, Chur, Switzerland. pp. 289-326.

HENICK-KLING, T., EDINGER, W., DANIEL, P. \& MONK, P., 1998. Selective effects of sulfur dioxide and yeast starter culture addition on indigenous yeast populations and sensory characteristics of wine. J. Appl. Microbiol. 84, 865-876. HEARD, G. \& FLEET, G., 1985. Growth of natural yeast flora during the fermentation of inoculated wines. Appl. Environ. Microbiol. 50, 727-728.

HEARD, G. \& FLEET, G., 1986. Occurrence and growth of yeast species during the fermentation of some Australian wines. Food Technol. Australia 38, 22-25.

HENSCHKE, P.A. \& JIRANEK, V., 1993a. Yeasts: Growth during fermentation. In: FLEET, G.H. (ed). Wine microbiology and biotechnology. Harwood Academic Publishers, Chur, Switzerland. pp. 27-54.

HENSCHKE, P.A. \& JIRANEK, V., 1993b. Yeasts: Metabolism of nitrogen compounds. In: FLEET, G.H. (ed). Wine microbiology and biotechnology. Harwood Academic Publishers, Chur, Switzerland. pp. 77-164.

HERESZTYN, T., 1984. Methyl and ethyl amino acid esters in wine. J. Agric Food Chem. 32, 916-918.

HERESZTYN, T., 1986. Formation of substituted tetrahydropyridines by species of Brettanomyces and Lactobacillus isolated from mousy wines. Am. J. Enol. Vitic. 37, 127-132.

HERRAIZ, T., MARTIN-ALVAREZ, P.J., REGLERO, G., HERRAIZ, M. \& CABEZUDO, M.D., 1989. Differences between wines fermented with and without sulphur dioxide using various selected yeasts. J. Sci. Food Agric. 49, 249-258. HERRAIZ, T. \& OUGH, C.S., 1992. Identification and determination of amino acid ethyl esters in wines by capillary gas chromatography-mass spectrometry. $J$. Agric. Food Chem. 40, 1015-1021.

HERRAIZ, T. \& OUGH, C.S., 1993. Formation of ethyl esters of amino acids by yeasts during the alcoholic fermentation of grape juice. Am. J. Enol. Vitic. 44, 4148.

HERRAIZ, T., REGLERO, G., HERRAIZ, M., MARTIN-ALVAREZ, P.J. \& CABEZUDO, M.D., 1990. The influence of the yeast and type of culture on the volatile composition of wines fermented without sulphur dioxide. Am. J. Enol. Vitic. 41, 313-318.

HOUTMAN, A.C. \& DU PLESSIS, C.S., 1981. Effect of juice clarity and several conditions promoting yeast growth on fermentation rate, the production of aroma compounds and wine quality. S. Afr. J. Enol. Vitic. 2, 71-81. 
HOUTMAN, A.C., MARAIS, J. \& DU PLESSIS, C.S., 1980a. The possibilities of applying present-day knowledge of wine aroma components: Influence of several juice factors on fermentation rate and ester production during fermentation. S. Afr. J. Enol. Vitic. 1, 27-33.

HOUTMAN, A.C., MARAIS, J. \& DU PLESSIS, C.S., 1980b. Factors affecting the reproducibility of fermentation of grape juice and of the aroma composition of wines. I. Grape maturity, sugar, inoculum concentration, aeration, juice turbidity and ergosterol. Vitis 19, 37-54.

JOHNSTON, J.M. \& PALTAUF, F., 1970. Lipid metabolism in inositol deficient yeast Saccharomyces carlsbergensis. II Incorporation of labeled precursors into lipids of whole cells and activities of some enzymes involved in lipid formation. Biochim. Biophys. Acta 218, 431-439.

KHAN, W., AUGUSTYN, O.P.H., VAN DER WESTHUIZEN, T.J., LAMBRECHTS, M.G. \& PRETORIUS, I.S., 2000. Geographic distribution and evaluation of Saccharomyces cerevisiae strains isolated from vineyards in the warmer, inland regions of the Western Cape in South Africa. S. Afr. J. Enol. Vitic. 21, 1731.

KING, A. \& DICKINSON, J.R., 2000. Biotransformation of monoterpene alcohols by Saccharomyces cerevisiae, Torulaspora delbreukii and Kluyveromyces lactis. Yeast 16, 499-506.

KURTZMAN, C.P. \& FELL, J.W., 1998. The yeasts: A toxonomic study. Elsevier, Amsterdam.

LAFON-LAFOURCADE, S., GENEIX, C. \& RIBÉREAU-GAYON. P., 1984. Inhibition of alcoholic fermentation of grape must by fatty acids produced by yeasts and their elimination by yeast ghosts. Appl. Environ. Microbiol. 47, 12461249.

LEAUTE, R., 1990. Distillation in alambic. Am. J. Enol. Vitic. 41, 90-103.

LEMA, C., GARCIA-JARES, C., ORRIOLS, I. \& ANGULO, L., 1996. Contribution of Saccharomyces and non-Saccharomyces populations to the production of some components of Albariño wine aroma. Am. J. Enol. Vitic. 47, 206216.

LILLY, M., LAMBRECHTS, M.G. \& PRETORIUS, I.S., 2000. Effect of increased yeast alcohol acetyltransferase activity on flavour profiles of wine and distillates. Appl. Environ. Microbiol. 66, 744-753.

LONGO, E, VELAQUEZ, J. B., SIEREIRO, C., CANSADO, J., CALO, P. \& VILLA, T. G., 1992. Production of higher alcohols, ethyl acetate, acetaldehyde and other compounds by 14 S.cerevisiae strains isolated from the same region (Salnes, NW Spain). Wld. J. Appl. Microbiol. Biotech. 8, 539-541.

LYNEN, F., 1967. The role of biotin-dependent carboxylations in biosynthetic reactions. Biochem. J. 102, 381-400.

MAARSE, H. \& VISSCHER, C.A., 1989. Volatile compounds in alcoholic beverages - qualitative and quantitative data. TNO-CIVO Food Analysis Institute, Zeist, The Netherlands.

MARAIS, J., 1978. The effect of pH on esters and quality of Colombar wine during maturation. Vitis 17, 396-403.

MARAIS, J., 1990. Wine aroma composition. Food Rev. 17, 18-21.

MARAIS, J. \& POOL, H.J., 1980. Effect of storage time and temperature on the volatile composition and quality of dry white table wines. Vitis 19, 151-164.

MASSOUTIER, C., ALEXANDRE, H., FEUILLAT, M. \& CHARPENTIER, C., 1998. Isolation and charaterization of cryotolerant Saccharomyces strains. Vitis 37, 55-59.

MATEO, J.J., JIMENEZ, M., HUERTA, T. \& PASTOR, A., 1991. Contribution of different yeasts isolated from musts of Monastrell grapes to the aroma of wine. Int. J. Food Microbiol. 14, 153-160.

MATEO, J.J., JIMENEZ, M., HUERTA, T. \& PASTOR, A., 1992. Comparison of volatiles produced by four Saccharomyces cerevisiae strains isolated from Monastrell musts. Am. J. Enol. Vitic. 43, 206-209.

MAURICIO, J.C., ARROYO, M. \& MILLAN, M., 1990. Relationship between the phospholipid and sterol contents in Saccharomyces cerevisiae and Torulaspora delbrueckii, and their permanence during the fermentation of musts from grapes of the "Pedro Ximinez" variety. Biotech. Lett. 12, 265-270.

MAURICIO, J.C., MORENO, J., LUIS, Z., ORTEGA, J.M. \& MEDINA, M., 1997. The effects of grape must fermentation conditions on volatile alcohols and esters formed by Saccharomyces cerevisiae. J. Sci. Food Agric. 75, 155-160.

MEWES, H.W., ALBERMANN, K., BÄHR, M., FRISHMAN, D., GLEISSNER, A., HANI, J., HEUMANN, K., KLEINE, K., MAIERL, A., OLIVER, S.G., PFERFFER, F. \& ZOLLNER, A., 1997. Overview of the yeast genome. Nature 387, 7-9.

MIRANDA-LOPEZ, R., LIBBEY, L.M., WATSON, B.T. \& McDANIEL, M.R., 1992. Identification of additional odour-active compounds in Pinot noir wines. Am. J. Enol. Vitic. 43, 83-87.
MONK, P.R. \& COWLEY, P.J., 1984. Effect of nicotinic acid and sugar concentration of grape juice and temperature on accumulation of acetic acid during yeast fermentation. J. Fermen. Techn. 62, 515-525.

MORA, J., BARBAS, J. \& MULET, A., 1990. Growth of yeast species during the fermentation of musts inoculated with Kluyveromyces thermotolerans and Saccharomyces cerevisiae. Am. J. Enol. Vitic. 41, 156-159.

NORDSTRÖM, K., 1962. Formation of ethyl acetate in fermentation with brewer's yeast. III. Participation of coenzyme A. J. Inst. Brew. 68, 398-407.

NORDSTRÖM, K., 1964a. Formation of esters from acids by brewer's yeast. II. Formation from lower fatty acids. J. Inst. Brew. 70, 42-55.

NORDSTRÖM, K., 1964b. Formation of esters from acids by brewer's yeast. IV. Effect of higher fatty acids and toxicity of lower fatty acids. J. Inst. Brew. 70, 233242.

NORDSTRÖM, K., 1964c. Formation of esters from alcohols by brewer's yeast. J. Inst. Brew. 70, 328-336.

NYKÄNEN, L., 1986. Formation and occurrence of flavour compounds in wine and distilled alcoholic beverages. Am. J. Enol. Vitic. 37, 84-96.

NYKÄNEN, L. \& NYKÄNEN, I., 1977. Production of esters by different yeast strains in sugar fermentations. J. Inst. Brew. 83, 30-31.

NYKÄNEN, L.L., NYKÄNEN, I. \& SUOMALAINEN, H., 1977. Distribution of esters produced during sugar fermentation between the yeast cell and the medium. J. Inst. Brew. 83, 32-34.

OLIVER, S.G., 1996. From DNA sequence to biological function. Nature 379, 597-600.

OUGH, C.S., COOK, J.A. \& LIDER, L.A., 1968. Rootstock-scion interactions concerning wine making. II. Wine compositional and sensory changes attributed to rootstock and fertilizer differences. Am. J. Enol. Vitic. 19, 254-265.

PALTAUF, F., KOHLWEIN, S.P. \& HENRY, S.A., 1992. Regulation and compartmentalization of lipid synthesis in yeast. In: JONES, E.W., PRINGLE, J.R. \& BROACH, J.R. (eds). The molecular and cellular biology of the yeast Saccharomyces: Gene expression. Cold Spring Harbor Laboratory Press. pp. 415500.

PEDDIE, H.A.B., 1990. Ester formation in brewery fermentations. J. Inst. Brew. 96, 327-331.

PEPPARD, T., 1988. Analytical measurement of volatile sulfur compounds in beer. In: LINKENS, H.F. \&. JACKSON, J.F (eds). Beer analysis. SpringerVerlag, Berlin. pp. 241-253.

PEYNAUD, E. \& GUIMBERTEAU, G., 1962. Sur la formation des alcools supérieurs pour les levures de vinification. Annales de Technologie Agricole 11, 85-105.

PEYNAUD, E. \& DOMERCQ, S., 1959. A review on microbiological problems in wine making in France. Am. J. Enol. Vitic. 10, 69-77.

PIENDL, A. \& GEIGER, E., 1980. Technological factors in the formation of esters during fermentation. Brew. Dig. 55, 26-35.

PIERCE, J. S., 1987. Horace Brown Memorial lecture: The role of nitrogen in brewing. J. Inst Brew. 93, 378-381.

PRETORIUS, I.S., 2000. Tailoring wine yeast for the new millennium: novel approaches to the ancient art of winemaking. Yeast 16, 675-729.

PRETORIUS, I.S., VAN DER WESTHUIZEN, T.J. \& AUGUSTYN, O.P.H., 1999. Yeast biodiversity in vineyards and wineries and its importance to the South African wine industry: A review. S. Afr. J. Enol. Vitic. 20, 61-74.

QUAIN, D.E., 1988. Studies on yeast physiology - Impact of fermentation performance and product quality. J. Inst. Brew. 94, 315-323.

RADLER, F., 1993. Yeasts- metabolism of organic acids. In: FLEET, G.H. (ed). Wine microbiology and biotechnology. Harwood Academic Publishers, Chur, Switzerland. pp. 165-182.

RAINBOW, C., 1970. In: ROSE \& HARRISON (eds). The yeasts. Academic Press, London \& New York. pp. 168-179.

RAMEY, D.D. \& OUGH, C.S., 1980. Volatile ester hydrolysis on formation during storage of model solutions and wines. J. Agric. Food Chem. 28, 928-934.

RANKINE, B.C., 1967. Formation of higher alcohols by wine yeasts, and relationship to taste thresholds. J. Sci. Food Agric. 18, 583-589.

RANKINE, B.C. \& POCOCK, K.F., 1969. b-Phenethanol and $n$-hexanol in wines: Influence of yeast strain, grape variety and other factors; and taste thresholds. Vitis 8, 23-37.

RAPP, A., 1998. Volatile flavour of wine: Correlation between instrumental analysis and sensory perception. Nahrung 42, 351-363.

RAPP, A. \& MANDERY, H., 1986.Wine aroma. Experentia 42, 873-884. 
RAPP, A. \& VERSINI, G., 1991. Influence of nitrogen compounds in grapes on aroma compounds of wine. In: RANTZ (ed). Proceedings of the International symposium on nitrogen in grapes and wines. Davis, CA: American Society for Enology and Viticulture. pp. 156-164.

RATLEDGE, C. \& EVANS, C.T., 1989. Lipids and their metabolism. In: The yeasts, vol. III. Academic Press Ltd. pp. 367-455.

RAUHUT, D., 1993. Yeasts - Production of sulfur compounds. In: FLEET, G.H. (ed). Wine microbiology and biotechnology, Chur, Switzerland. pp. 183-223.

RAUHUT, D. \& KÜRBEL, H., 1994a. Die Enstehung von $\mathrm{H}_{2} \mathrm{~S}$ aus Netzschwefelrückständen während der Gärung und dessen einflub auf die Bildung von Böckserverursachenden Schwefelhaltigen Metaboliten in Wein. Vitic. Enol. Sci. 49, 27-36.

RAUHUT, D. \& KÜRBEL, H., 1994b. Analysis of volatile sulfur compounds in wine using gas chromatography with a sulfur chemiluminescence detector. Sixteenth International Symposium on Capillary Chromatogrophy, Riva del Garda, Italy. pp. 732-741.

RAUHUT, D. \& KÜRBEL, H., 1996. Identification of wine aroma defects caused by sulfur-containing metabolites of yeasts. I $n$ : Enologie 95, $5^{\mathrm{e}}$ Symposium International d'œnologie, Bordeaux-Lac, Coordonnateur Lonvaud-Funel, A., Technique \& Documentation: Londres, Paris, New York. pp. 515-519.

RAUHUT, D., KÜRBEL, H., DITTRICH, H.H. \& GROSSMANN, M.K., 1996. Properties and differences of commercial yeast strains with respect to their formation of sulfur compounds. Vitic. Enol. Sci. 51, 187-192.

RAUHUT, D., SPONHOLZ, W.R. \& DITTRICH, H.H., 1986. Beeinflussen Pflanzenschutzmittel die Weinqualität? Der Deutsche Weinbau 16, 872-874.

RAVAGLIA, S. \& DELFINI, C., 1993. Production of medium chain fatty acids and their ethyl esters by yeast strains isolated from musts and wines. Ital. J. Food Sci. 5, 21-36.

REAZIN, G., SCALES, H. \& ANDREASON, A.A., 1970. Mechanism of major congener formation in alcoholic grain fermentations. J. Agric. Food Chem. 18, 585-589.

REAZIN, G., SCALES, H. \& ANDREASON, A.A., 1973. Production of higher alcohols from threonine and isoleucine in alcoholic fermentations of the different types of grain mash. J. Agric. Food Chem. 21, 50-54.

RENGER, R.S., VAN HATEREN, S.H. \& LUYBEN, K.A.M., 1992. The formation of esters and higher alcohols during brewery fermentation; the effect of carbon dioxide pressure. J. Inst. Brew. 89, 271-278.

RIBÉREAU-GAYON, P., GLORIES, Y., MAUGEAN, A. \& DUBOURDIEU, D., 1998. Tome 2, Chimie du vin, stabilisation et traitements. Dunod, Paris.

RIBÉREAU-GAYON, J., PEYNAUD, E., RIBÉREAU-GAYON, P. \& SUDRAUD, P., 1982. Sciences et Techniques du Vin, Tome I, Analyse et contrôle des Vins. Dunod, Paris.

RIESEN, R., 1992. Undesirable fermentation aromas. Proc. of the ASEV/ES workshop: Wine aroma defects. T. HENICK-KLING (ed). Corning, NY: American Society of Enology \& Viticulture. pp. 1-43.

ROBINSON, J., 1994. The Oxford Companion to Wine. Oxford University Press, Oxford.

ROMANO, P., SUZZI, G., TURBANTI, L. \& POLSINELLI, M., 1994 Acetaldehyde production in Saccharomyces cerevisiae wine yeasts. FEMS Microbiol. Lett. 118, 213-218.

ROSI, I. \& BERTUCCIOLI, M., 1992. Influences of lipid addition on fatty acid composition of $S$. cerevisiae and aroma characteristics of experimental wines. $J$. Inst. Brew. 98, 305-314.

ROSI, I., CONTINI, M. \& BERTUCCIOLI, M., 1989. Relationship between enzymatic activities of wine yeasts and aroma compound formation. Flavours and off flavours. Proc. $6^{\text {th }}$ Int. Flavour 103 Conference, Elsevier Sci. Pub. pp. 103120.

SA-CORREIA, I., SALGUEIRO, S.P., VIEGAS, C.A. \& NOVAIS, J.M., 1989. Leakage induced by ethanol, octanoic and decanoic acids in Saccharomyces cerevisiae. Yeast 5, 123-127.

SALO, P., 1970a. Determining the odor thresholds for some compounds in alcoholic beverages. J. Food Sci. 35, 95-99.

SALO, P., 1970b. Variability of odour thresholds for some compounds in alcoholic beverages. J. Sci. Food Agric. 21, 597-600.

SCHEFFERS, W.A., 1987. Alcoholic fermentation. Studies in Mycology 30, 321332.

SCHREIER, P., 1979. Flavour composition of wines: a review. CRC Crit. Rev. Food Sci. Nutr. 12, 59-111.
SCHREIER, P., DRAWERT, F., JUNKER, A., BARTON, H. \& LEUPOLD, G., 1976. Uber die Biosynthese von Aromastoffen durch Mikroorganismen. II. Bildung von Schewefelverbindungen aus Methionin durch Saccharomyces cerevisiae. Zeitschrift für Lebensmittel Unterrsuchung und Forschung 162, 279-284. SCHUTTE, L., 1975. Precursors of sulfur-containing flavor compounds. In: FURIA, T.E \& BELLANCA, N. (eds). Fenaroli's handbook of flavor ingredients. CRC Press, Cleveland, Ohio. pp. 184-227.

SCHULTHESS, D. \& ETTLINGER, L., 1978. Influence of the concentration of branched chain amino acids on the formation of fusel alcohols. J. Inst. Brew. 84, 240-243.

SCHÜTZ, M. \& KUNKEE, E., 1977. Formation of hydrogen sulfide from elemental sulfur during fermentation by wine yeast. Am. J. Enol. Vitic. 28, 137-144. SHINOHARA, T. \& WATANABE, M., 1976. Gas chromatographic analysis of higher alcohols and ethyl acetate in table wines. Agric. Biol. Chem. 40, 24752477.

SIMPSON, R.F. \& MILLER, G.C., 1984. Aroma composition of Chardonnay wine. Vitis 23, 143-158.

SINGLETON, V.L. \& ESAU, P., 1969. Phenolic substances in grapes and wine and their significance. Adv. Food Res. 1, 1-282.

SODEN, A., FRANCIS, I.L., OAKEY, H. \& HENSCHKE, P.A., 2000. Effects of co-fermentation with Candida stellata and Saccharomyces cerevisiae on the aroma and composition of Chardonnay wine. Austr. J. Wine Res. 6, 21-30.

SOLES, R.M., OUGH, C.S. \& KUNKEE, R.E., 1982. Ester concentration differences in wine fermented by various species and strains of yeasts. Am. J. Enol. Vitic. 33, 94-98.

SOLTOFT, M., 1988. Flavour active sulfur compounds in beer. Brygmesteren 2 , 18-248.

SPONHOLZ, W.-R., 1993. Wine spoilage by microorganisms. In: FLEET, G.H. (ed). Wine microbiology and biotechnology. Chur, Switzerland. pp. 395-420.

STEGER, C.L.C. \& LAMBRECHTS, M.G., 2000. The selection of yeast strains for the production of premium quality South African brandy base products. J. Ind. Microbiol. Biotech. 24, 1-11.

STRATFORD, M. \& ROSE, A.H., 1986. Transport of sulphur dioxide by Saccharomyces cerevisiae. J. Gen. Microbiol. 132, 1-6.

STRAUSS, M.L.A., LAMBRECHTS, M.G., JOLLY, N.P., VAN RENSBURG, P. \& PRETORIUS, I.S., 2000. Screening for the production of extracellular hydrolytic enzymes by non-Saccharomyces wine yeasts. S. Afr. J. Enol. Vitic. (submitted)

SUOMALAINEN, H. \& LEHTONEN, M., 1979. The production of aroma compounds by yeast. J. Inst. Brew. 85, 149-156.

THEN, R \& RADLER, F., 1971. Vergleichende Untersuchunhg der Acetaldehydbildung bei der aroben Vergärung von Glucose bei verscheidenen Stämmen von Saccharomyces cerevisiae und Saccharomyces carlsbergensis. Mschr. Brauerei 24, 127-130.

THURSTON, P.A., TAYLOR \& AHVENAINEN, J., 1981. Effects of linoleic acid supplements on the synthesis by yeast of lipids and acetate esters. J. Inst. Brew. 87, 92-95.

THURSTON, P.A., QUAIN, D.E. \& TUBB, R.S., 1982. Lipid metabolism and the regulation of volatile ester synthesis in Saccharomyces cerevisiae. J. Inst. Brew. 88, 90-94.

TOMINAGA, T., DARRIET, P. \& DUBOURDIEU, D., 1996. Identification of 3mercaptohexyl acetate in Sauvignon wine, a powerful aromatic compound exhibiting box-tree odor. Vitis 35, 207-210.

TOMINAGA, T., FURRER, A., HENRY, R.. \& DUBOURDIEU, D., 1998a. Identification of new volatile thiols in the aroma of Vitis vinifera L. var. Sauvignon blanc wines. Flavour Fragrance J. 13, 159-162

TOMINAGA, T., PEYROT DES GACHONS, C. \& DUBOURDIEU, D., $1998 \mathrm{~b}$. A new type of flavour precursors in Vitis vinifera L. cv. Sauvignon blanc: S-cysteine conjugates. J. Agric. Food Chem. 46, 5215-5219.

VAN DER MERWE, C.A. \& VAN WYK, C.J., 1981. The contribution of some fermentation products to the odor of dry white wines. Am. J. Enol. Vitic. 32, 4146.

VAN DER WESTHUIZEN, T.J., AUGUSTYN, O.P.H., KHAN, W. \& PRETORIUS, I.S., 2000a. Seasonal variation of indigenous Saccharomyces cerevisiae strains isolated from vineyards of the Western Cape in South Africa. S. Afr. J. Enol. Vitic. 21, 10-16.

VAN DER WESTHUIZEN, T.J., AUGUSTYN, O.P.H. \& PRETORIUS, I.S., 2000b. Geographical distribution of indigenous Saccharomyces cerevisiae strains isolated from vineyards in the coastal regions of the Western Cape in South Africa. S. Afr. J. Enol. Vitic. 21, 3-9. 
VAN DIJKEN, J.P. \& SCHEFFERS, W.A., 1986. Redox balances in the metabolism of sugars by yeasts. FEMS Microbiol. Rev. 32, 199-224.

VAN ROOYEN, P.C., DE WET, P., VAN WYK, C.J. \& TROMP, A., 1982. Chenin blanc wine volatiles and the intensity of a guava-like flavour. S. Afr. J. Enol. Vitic. 3, 1-7.

VAN WYK, C.J., AUGUSTYN, O.P.H., DE WET, P. \& JOUBERT, W.A., 1979. Isoamyl acetate - a key fermentation volatile of wines of Vitis vinifera cv Pinotage. Am. J. Enol. Vitic. 30, 167-173.

VAN WYK, C.J. \& ROGERS, I.M., 2000. A "Phenolic" off-odour in white table wines: causes and methods to diminish its occurrence. S. Afr. Enol. Vitic. 21, 5257.

VEENHUIS, M., MATEBLOWSKI, M., KUNAU, W.H. \& HARDER, W., 1987. Proliferation of microbodies in Saccharomyces cerevisiae. Yeast 3, 77-82.

VIEGAS, C.A., ROSA, M.F., SA-CORREIA, I. \& NOVAIS, J.M., 1989. Inhibition of yeast growth by octanoic and decanoic acids produced during ethanolic fermentation. Appl. Environ. Microbiol. 55, 21-28.

VOLLBRECHT, D. \& RADLER, F., 1973. Formation of higher alcohols by amino acid deficient mutants of Saccharomyces cerevisiae. I. The decomposition of amino acids to higher alcohols. Arch. Mikrobiol. 94, 351-358.
VOS, P.J.A. \& GRAY, R.S., 1979. The origin and control of hydrogen sulfide during fermentation of grape must. Am. J. Enol. Vitic. 30, 187-197.

WALENGA, R.W. \& LANDS, W.E.M., 1975. Effectiveness of various unsaturated fatty acids in supporting growth and respiration in S. cerevisiae. J. Biol. Chem. 250, 9121-9129.

WALKER, G.M., 1998. Yeast physiology and biotechnology. John Wiley \& Sons, Chichester, England.

WEBB, A.D. \& INGRAHAM, J.L., 1963. Fusel oil. Adv. Appl. Microbiol. 5, 317353.

WEBB, A.D. \& KEPNER, R.E., 1961. Fusel oil analysis by means of gas liquid partition chromatography. Am. J. Enol. Vitic. 12, 51-59.

YOSHIOKA, K. \& HASHIMOTO, N., 1983. Cellular fatty acid and ester formation by brewers' yeast. Agric. Biol. Chem. 47, 2287-2294.

ZEA, L., MORENO, J., MEDINA, M. \& ORTEGA, J.M., 1994. Evolution of $\mathrm{C}_{6}$, $\mathrm{C}_{8}$ and $\mathrm{C}_{10}$ acids and their ethyl esters in cells and musts during fermentation with three Saccharomyces cerevisiae races. J. Industrial Microbiol. 13, 269-272.

ZOECKLEIN, B.W., FUGELSANG, K.C., GUMP, B.H. \& NURY, F.S., 1995 Alcohol and extract. In: Wine analysis and production. The Chapman and Hall Enology Library. pp. 97-114. 